Portland State University

PDXScholar

\title{
The Use of the California Consonant Test and the Northwestern University Auditory Test no. 6 in Hearing Aid Evaluations for Individuals with Precipitous Losses Above $1 \mathrm{kHz}$
}

\author{
Bradley James Allard
}

Portland State University

Follow this and additional works at: https://pdxscholar.library.pdx.edu/open_access_etds

Part of the Speech and Hearing Science Commons, and the Speech Pathology and Audiology Commons

Let us know how access to this document benefits you.

\section{Recommended Citation}

Allard, Bradley James, "The Use of the California Consonant Test and the Northwestern University Auditory Test no. 6 in Hearing Aid Evaluations for Individuals with Precipitous Losses Above $1 \mathrm{kHz}$ (1990). Dissertations and Theses. Paper 3953.

https://doi.org/10.15760/etd.5837

This Thesis is brought to you for free and open access. It has been accepted for inclusion in Dissertations and Theses by an authorized administrator of PDXScholar. Please contact us if we can make this document more accessible: pdxscholar@pdx.edu. 
AN ABSTRACT OF THE THESIS OF Bradley James Allard for the Master of Science in Speech Communication: Speech and Hearing Sciences presented February 7, 1990

Title: The Use of the California Consonant Test and the Northwestern University Auditory Test No. 6 in Hearing Aid Evaluations for Individuals with Precipitous Losses above $1 \mathrm{kHz}$.

APPROVED BY THE MEMBERS OF THE THESIS COMMITTEE:

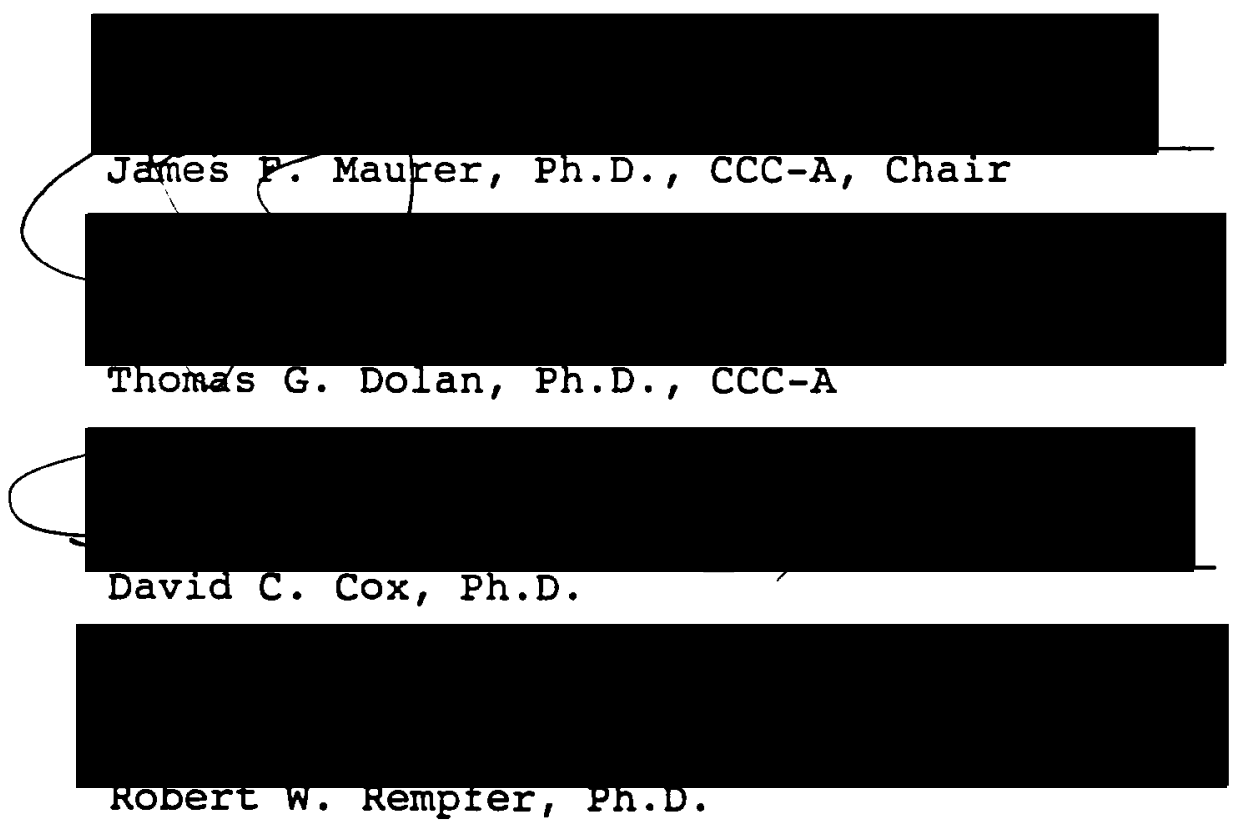

These two joint-studies used recorded versions of the Northwestern University Auditory Test Number $6(\mathrm{NU}-6)$ and the California Consonant Test (CCT) in the hearing aid evaluations (HAEs) of 12 male and one female subjects, aged 
41 to 87 years. They exhibited precipitous high frequency losses beyond $1 \mathrm{kHz}$ in at least one ear. All subjects were evaluated without amplification and while monaurally aided with two conventional high pass hearing aids. Ten of the subjects were evaluated in multi-talker noise and 11 were tested in quiet. Since the CCT was more heavily weighted than the NU-6 with target phonemes sensitive to high frequency losses, it was hypothesized that the CCT might be more sensitive than the NU-6 to significant differences between aided and/or unaided performances of these particularly high frequency impaired subjects.

The data collected in noise and in quiet was analyzed separately with the one-way analysis of variance (ANOVA) for repeated measures. No significant differences were found in noise or quiet between the aided performances on either the CCT or the NU-6. The NU-6 in noise, however, revealed significant degrees of aided improvement at the .01 level of confidence that the CCT did not. The addition of noise seemed to make the CCT too difficult for these subjects. In quiet, both tests seemed to be as equally sensitive in revealing significant aided improvement at the .01 level of confidence. The lower mean CCT scores in quiet, however, seemed to indicate that if unaided NU-6 performances are too high to allow for significant aided improvement or significant differences between aids, the more time consuming CCT might be appropriate. 
THE USE OF THE CALIFORNIA CONSONANT TEST AND THE NORTHWESTERN UNIVERSITY AUDITORY TEST NO. 6 IN HEARING AID EVALUATIONS FOR INDIVIDUALS WITH PRECIPITOUS LOSSES ABOVE $1 \mathrm{kHz}$

\author{
by \\ BRADLEY JAMES ALTIARD
}

A thesis submitted in partial fulfillment of the requirements for the degree of

MASTER OF SCIENCE

in

SPEECH COMMUNICATION/SPEECH AND HEARING SCIENCES

Portland State University

1990 
TO THE OFFICE OF GRADUATE STUDIES:

The members of the Committee approve the thesis of Bradley James Allard presented February 7, 1990.

Janes F\& Maurer, Chair

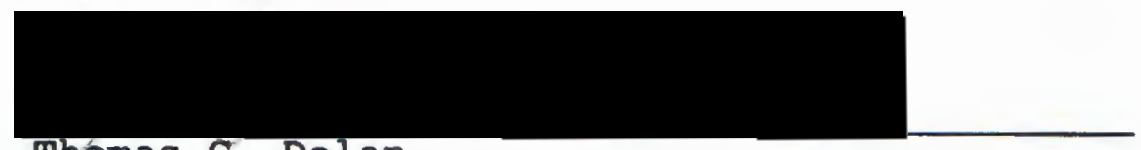

Thomas G. Dolan

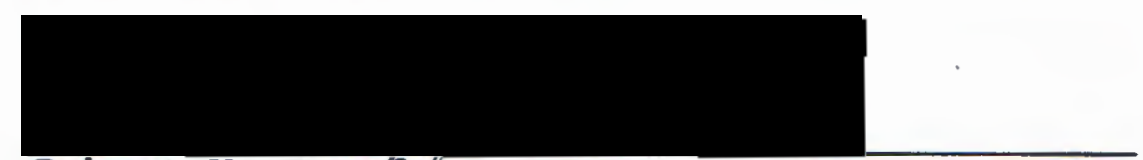

Robert w. Rempier

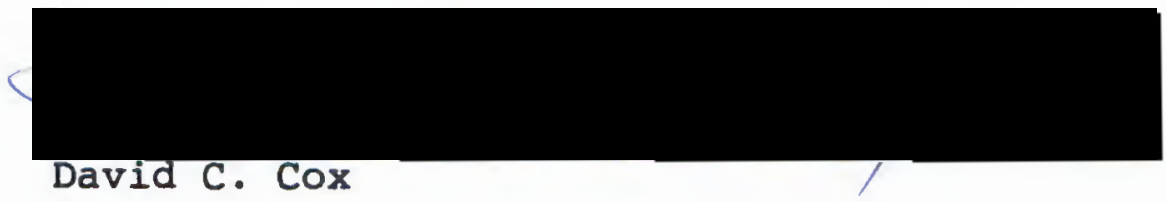

APPROVED:

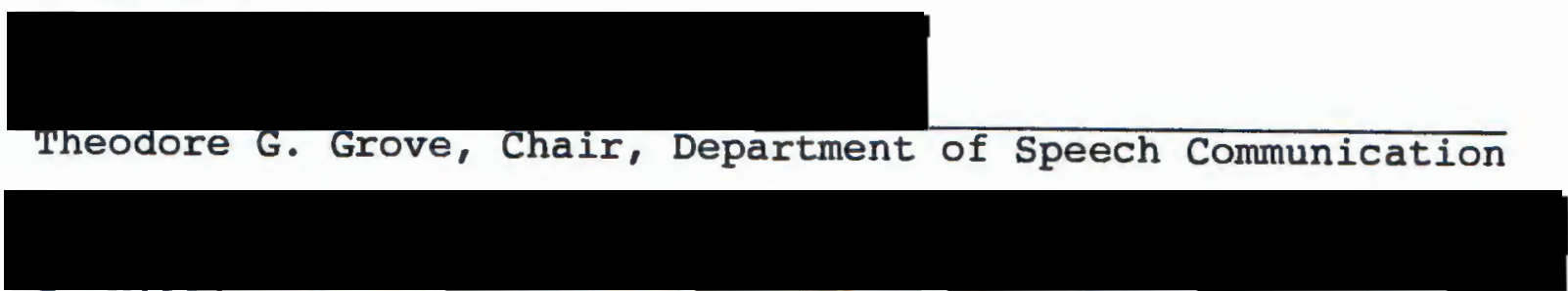

C. William Savery, Interim Vice Provost for Graduate Studies and Research 


\section{ACKNOWLEDGMENTS}

The author wishes to express his appreciation to the many people whose input, suggestions and support helped to make this project possible. The subjects themselves donated many serious yet monotonous hours providing the raw data necessary to make these studies possible. The distinguished members of the committee as mentors and friends helped guide the author through the many complicated steps that lead to this final manuscript. The author's family members and friends, through their support, patience and encouragement enabled him to persevere as he anguished over his frustrating tasks. 
TABLE OF CONTENTS

PAGE

ACKNOWLEDGMENTS . . . . . . . . . . . . . . iii

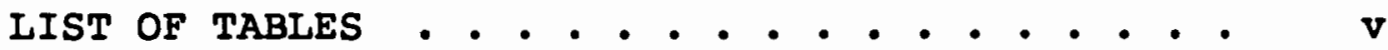

LIST OF FIGURES . . . . . . . . . . . . . . vii

CHAPTER

I INTRODUCTION

II DISCRIMINATION TESTS USED IN HEARING

AID EVALUATIONS . . . . . . . . . . 6

II METHODS . . . . . . . . . . . . 45

Subjects . . . . . . . . . . 45

Instrumentation ....... 46

Procedures ........... . 47

IV RESULTS AND DISCUSSION . . . . . . . 51

Results . . . . . . . . . 51

Discussion . . . . . . . . 65

V SUMMARY AND IMPLICATIONS ... . . . 68

Summary . . . . . . . . . 68

Implications . . . . . . . 70

SELECTED REFERENCES • . . . . . . . . . . • 75 APPENDICES

A. INDIVIDUAL SUBJECT SCORES FOR UNAIDED AND AIDED CONDITIONS IN NOISE . . . .

B. INDIVIDUAL SUBJECT SCORES FOR UNAIDED AND AIDED CONDITIONS IN QUIET . . . . 


\section{IIST OF TABLES}

TABLE

PAGE

I. Probabilities of Phonemic Error in

the California Consonant Test (CCT) . .

II. Mean $\mathrm{W}-22$ and Test 6 Percentage Scores

For Several Audiometric

Configurations

III. Probability of Error on Phonemes

Sensitive To High Frequency

Losses

IV. Probability of Error on Phonemes

Less Sensitive To High Frequency

Losses

v. Quantities of Test Phonemes in the

California Consonant

Test (CCT)

VI. Probability of Error for CCT

Target Phonemes . . . .

VII. Sound Field Discrimination Results

of High Frequency

Impaired Subjects . . . . . . . . .

VIII. Mean Aided Improvement in

Discrimination Scores of

High Frequency Impaired Subjects . .

IX. Mean Aided Results and Standard

Deviations for SUD

Estimated $S / N(s)$ That would

Yield $50 \%$ CCT Scores and

CCT Scores Obtained at

the Respective $S / N(s)$

X. Mean Audiometric Thresholds in $\mathrm{db}$ fIL

of Subjects Receiving

Hearing Aid Evaluations

(HAEs) In Noise . . . . . . . . . . . 
XI. Mean Audiometric Thresholds in $\mathrm{db} \mathrm{HL}$ of Subjects Receiving

Hearing Aid Evaluations

(HAEs) In Quiet . . . . . . . . . .

XII. Means, Standard Deviations and

Ranges of NU-6 Discrimination

Percentage Scores Evaluated

in Noise and Quiet

Obtained at MCL With Headphones . . .

XIII. Unaided and Aided Mean

Discrimination Percentage

Scores, Standard Deviations and

Ranges of Subjects with

Precipitous High Frequency

Losses, Tested in Noise . . . . . . .

XIV. Unaided and Aided Mean Discrimination

Percentage Scores, Standard

Deviations and Ranges of Subjects

With Precipitous High Frequency

Losses, Tested in Quiet. . . . . . . .

XV. Aided Improvement in Discrimination

Percentage Scores of Subjects

With Precipitous High

Frequency Losses . . . . . . . . .

XVI. One Way Analysis of Variance

For Repeated Measures (ANOVA)

For Unaided and Aided

CCT and NU-6 Scores

of Subjects Evaluated in Noise . . . .

XVII. One Way Analysis of Variance For epeated Mećures (ANOVA) For

Unaided and Aided CCT and NU-6 Scores of Subjects Evaluated in Quiet . . . . 


\section{LIST OF FIGURES}

\section{FIGURE}

PAGE

1. Schematics for selecting pure tone configurations in Owens and Schubert (1968) . . . . . . . . . . 27

2. Mean 2cc hard wall coupler frequency responses of the two instruments used with each subject . . . . . . .

3. Mean real ear aided and unaided frequency responses for 7 of 10 subjects with $\mathrm{HAE}$ (s) conducted in noise . . . . . . . . .

4. Mean real ear aided and unaided frequency responses for 7 of 11 subjects with $\operatorname{HAE}(s)$ conducted in quiet . . . . . . . .

5. Mean real ear gain levels, as measured by a probe microphone, for 7 of 10 subjects with $\operatorname{HAE}(\mathrm{s})$ conducted in noise for Bosch Star 66F-H; Unitron UE $10 \mathrm{H}$. . . . . . . . . . .

6. Mean real ear gain levels, as measured by a probe microphone, for 7 of 11 subjects with $\operatorname{HAE}(s)$ conducted in quiet. Bosch Star $66 \mathrm{~F}-\mathrm{H}$; Unitron UE $10 \mathrm{H}$ 
CHAPTER I

\section{INTRODUCTION}

Carhart introduced the comparative hearing aid evaluation (HAE) in 1946. Since then, not only have hearing aids changed drastically in type and physical appearance, but their acoustic properties and available adjustments have been improved and diversified.

The ability to distinguish small differences in sound is of primary importance to hearing aid user(s). It is, therefore, necessary to have a good estimate of the relative discrimination which the wearer achieves with different hearing aids (Carhart, 1946).

To make such estimates, a variety of speech tests have been clinically administered at various sound levels in quiet and in various levels and types of noise. These tests have been administered in both aided and unaided conditions such that improvements in the detection and understanding of speech provided with various hearing aids could be measured and compared (Ross, 1978). Speech tests have been applied in $\operatorname{HAE}(\mathrm{s})$ to estimate what benefits or lack of benefits an individual could expect from amplification in his daily life. To help replicate the often difficult acoustic conditions a hearing aid user could expect to encounter, speech discrimination tests of varied difficulty have been 
developed. Noise has been simultaneously presented with recorded or spoken word lists to additionally help simulate the difficult listening environments that hearing aid users could anticipate.

Many studies have related the segmental aspects of the speech spectrum to the intelligibility of speech (Harris, et al., 1960; Owens, et al., 1972; Gerber, 1974; Sher and Owens, 1974; Chari, et al., 1977; Owens and Schubert, 1977; and Schwartz and Surr, 1979). While most acoustic energy of speech is concentrated below $1 \mathrm{kHz}$ and originates with the vowels, the majority of speech clarity is obtained with the consonant sounds, above $1 \mathrm{kHz}$ (Gerber, 1974). This has meant that until the advent of high frequency amplification, individuals with the greatest impairment beyond $1 \mathrm{kHz}$ were condemned to unaided lives where they could hear but not understand many of the things said to them. This was particularly the case when normal thresholds were exhibited through $1 \mathrm{kHz}$ followed by precipitous losses that abruptly commenced at $2 \mathrm{kHz}$ and beyond.

As hearing aids with high pass filter networks were developed to accommodate these frustrating impairments, it was found that ever more sophisticated discrimination tasks would be helpful to reveal aided improvements and especially to reveal significant differences between high frequency emphasis hearing aids. 
The Northwestern University auditory test No. 6 (NU-6) (Speaks and Jerger, 1965), with its purported phonemic balance of the English language, has been used widely in hearing aid evaluations (HAE's). It was designed as a substitute for the phonetically balanced CID auditory Test W-22, which was a modification of the Psycho-Acoustic Laboratories PAL PB-50 word list (Hirsh, et al. 1952).

Owens and Schubert (1977) introduced the California consonant test (CCT) as a clinical tool which targeted phonemes more often missed by individuals with high frequency hearing losses than the majority of phonemes targeted by the NU-6, CID $\mathrm{W}-22$ and PAL PB-50 tests. Because the CCT was more heavily weighted with such phonemes, it may be a better tool for $\operatorname{HAE}(\mathrm{s})$ on individuals with particularly high frequency losses. Sher and Owens (1974), Schwartz and Surr (1979), Danhauer and Leppler (1979) and Surr and Schwartz (1980) have evaluated the CCT by itself and in comparison to the NU-6 on individuals with high frequency losses, in quiet as well as in a variety of types and levels of noise.

Schwartz, et al. (1979) compared the aided improvements born by an extended high pass aid and conventional high pass aids using the CCT and the NU-6 (as well as a nonsense syllable test) in noise and in quiet. But instead of finding the CCT to be more sensitive to aided differences than the NU-6, they found that both tests revealed 
equivalent levels of aided improvement with the extended high pass instrument over the conventional aids. But the two tests were only able to reveal this improvement when they were presented in noise, not when they were presented in quiet.

However, the subjects evaluated by Schwartz, et al. (1979) exhibited mean thresholds that were normal through $1 \mathrm{kHz}$ with losses sloping from mild at $2 \mathrm{kHz}$ to severe in the higher frequencies. It is possible that these losses were not precipitous enough to exhibit a difference between the two tests. That is, their perception of phonemes may not have degraded enough to reveal extra benefits with the CCT over the NU-6. The question arises as to what would occur if the CCT and NU-6 were used in $\operatorname{HAE}(\mathrm{s})$ on individuals with even steeper high frequency losses. Would the CCT, based on its phonemic content, be more sensitive than the NU-6 to varied degrees of aided improvement for individuals with such extreme high frequency impairments?

To address this question, the joint studies described herein were patterned after the one by Schwartz, et al. (1979). As in Schwartz, et al. (1979), hearing aid evaluations were conducted in quiet and in noise on individuals with high frequency hearing losses. But the acoustic differences between the hearing aids used in this study were smaller than those analyzed by Schwartz, et al. (1979). Both aids in this study were conventional high pass 
instruments whereas one of those used in Schwartz, et al. (1979) was an extended high pass aid. More critically, though, the high frequency impairments evaluated in this study exhibited a more precipitous drop to their audiometric configuration than the impairments evaluated in Schwartz, et al. (1979). The question was asked: could mean CCT or NU6 results in noise or in quiet reveal a statistically significant difference between paired aided performances or between unaided-aided performances of these particularly high frequency impaired subjects or would the acoustic differences be too small to be reflected in the mean subject performances?

It was reasoned that since the CCT was designed to be sensitive to the phonemic errors associated with high frequency impairments, an ideal way to compare its effectiveness with the NU-6 would be to test individuals with an "extreme" type of high frequency loss. It was for that reason that subjects with normal hearing through $1 \mathrm{kHz}$ followed by precipitous moderate to severe losses at $2 \mathrm{kHz}$ and beyond were the focus of the study described in this paper. 
CHAPTER II

\section{DISCRIMTNATION TESTS USED IN HEARING AID EVALUATIONS}

The many types of speech discrimination tests used in the evaluation of hearing aids have been shown to bear varying degrees of difficulty on the subjects to which they were applied. Miller, et al. (1951) compared the percentage correct scores of nonsense syllables, monosyllabic words in insolation, sentences with five key words and the ten single digits 0 through 9 as they were presented in signal to noise ratios ( $\mathrm{S}: \mathrm{N}$ ) ranging from -18 to $+18 \mathrm{~dB}$. The 10 single digits yielded the highest scores throughout the continuum of noise levels because the variance of their relatively intense vowel sounds made them easy to differentiate. At the respective $S: N$ ratios, words in isolation produced lower scores than the same words used in sentences and nonsense syllables yielded the lowest scores of all, since each phoneme had to be understood before the syllables were correctly identified. Miller, et al. (1951) also found that the intelligibility scores for monosyllabic words decreased as a function of the size of the text vocabularies from which they were chosen. This occurred when the subjects were familiarized beforehand with test items as they appeared in lists ranging in sizes of $2,4,8,16,32$ and 
256 words. In a study of normal listeners using $1 / 3$ octaveband filters, Danhauer, et al. (1977) supported the Miller, et al. (1951) conclusions. They found that discrimination became progressively more difficult as the subjects listened to words in sentences, monosyllabic consonant, vowel, consonant syllables CVC(s) in isolation and individual CV syllables.

The most common speech discrimination tests used in hearing aid evaluations are the contextually free but meaningful monosyllabic words. The first of those to be used widely was formulated at Harvard Psycho-Acoustic Laboratories and known as the PAL PB-50 word lists. Egan (1948) published 2050 word lists, having tried to equalize both their average difficulty and range of difficulty. The initial phonemes of the words were reported to have been phonetically balanced. That is, it was attempted to make the lists representative of the proportional use of phonemes as found in common, familiar daily English speech (Goetzinger, 1978). A St. Louis professional announcer, Rush Hughes, later made standardized disk recordings of eight of these original 20 lists (Penrod, 1985) in an effort to eliminate the voice variations of different speakers as well as the variances encountered when single speakers make several presentations.

Eldert and Davis (1951) and Hirsh, et al. (1952), however, noted that many of the words in the PAL PB-50 
recordings lacked sufficient familiarity and that the recordings were poorly standardized. In response, Hirsh et al. (1952) modified the PAL PB-50 word lists to form the four separate lists known as the CID Auditory Test W-22. Efforts were made to improve the familiarity of the words used and to better standardize the recordings. By use of magnetic master tapes, six scramblings of each list were made available.

From 1959 through 1966 a succession of studies resulted in the development of the Northwestern University Auditory Test No. 6 (NU-6) (Tillman and Carhart, 1966). This collection of four 50 word lists was developed under the belief that a phonetic balance of English sounds is impossible because of the variances experienced with those sounds due to their coarticulation with adjacent sounds. In contrast to the $\mathrm{PAI} \mathrm{PB}-50$ and $\mathrm{CID} \mathrm{W}-22$ recordings, therefore, the NU-6 lists were a collection of consonantnucleus (vowel)-consonant (CNC) monosyllabic words that were chosen to represent a phonemic balance of the English language. That is, the individual sounds that comprise English were represented in proportion to how they were coarticulated with each other rather than how often they individually appeared in everyday use. Currently, these lists are used widely in clinical and research facilities. Fairbanks (1958) developed a closed response set monosyllabic speech discrimination test that consisted of 
six equivalent 50 word lists. Although phonetic or phonemic balancing was not a goal, the individual lists had consistent phonetic compositions and each contained representatives from the major speech sound classes (House, et al., 1965). The 18 consonant phonemes utilized represented only $90 \%$ of the English consonants. Important high frequency sounds such as $\theta, d_{,} \int$ and $t \int$ were excluded. A common familiarity of the test items was not deemed important because the possible responses for each was provided in writing to the listener beforehand. Most of the words had a consonant, a vowel and then a consonant (CVC), although some had only a consonant followed by a vowel (CV) or a vowel followed by a consonant (VC). The multiple choice responses had the same sounds as the test items except for the target phonemes (Fairbanks, 1958; House 1965; Kreul, et al., 1968 and 1969).

The Modified Rhyme test by House, et al. (1965) differed slightly from Fairbank's original in regard to the nature of the listening task as well as to the constraints imposed on the words and the word lists. It was attempted to equalize the phonetic composition of the half lists. Kreul, et al. (1968) made further modifications, keeping the needs of the clinical audiologist in mind. Changes were made in terms of the recording technique, speaker control, carrier phrase, masking levels and answer sheets. An effort to equate performance levels that differed due to speaker 
variances was made by applying slightly different $\mathrm{S} / \mathrm{N}$ ratios to the recordings of the various speakers.

In addition to the varied, monosyllabic speech discrimination tests, a number of multiword tests also have been used in hearing aid evaluations. Meaningful sentence tests such as Utley's (1946), Barley's CID everyday sentences (Jeffers and Barley, 1976), the Denver Quick test (Alpiner, 1982) and others have been formulated to evaluate a listener's ability to understand speech given the help of semantic and contextual cues. This type of test can be scored analytically and/or synthetically. Dodds and Harford (1968) recommended the use of sentence tests when evaluating the auditory speech functions of those with poor or borderline auditory capabilities. But as noted by Miller, et al. (1951), the inherent redundancies made such tasks too easy for most listeners and were of little use in most clinical hearing aid evaluations.

The Synthetic Sentence Identification test (SSI) was developed by Speaks and Jerger (1965). It may be used in both central testing and hearing aid evaluations to measure an individual's ability to perceive the changing patterns of running speech while minimizing the effects of semantic and contextual cues. It consists of several randomized lists of 10 third order approximations to real sentences "characterized by the dependency of any word on the two words which precede it (Goetzinger, 1978)." A sample 
synthetic sentence is "Women view men with green paper should." (Speaks and Jerger 1965).

Jerger and Hayes (1976) used the SSI to evaluate aided performances in six message to competition ratios (MCR) ranging from -20 to $+20 \mathrm{~dB} \mathrm{~S} / \mathrm{N}$. Their results indicated that when used in more difficult $\operatorname{MCR}(s)$, the SSI showed promise as an index of a hearing aid user's real life satisfaction regardless of the degree of his or her impairment. They offered it as a more valid approximation of real speech than the traditional monosyllabic word lists. Hayes, et al. (1983) reported that at -10 dB MCR there was more than a $30 \%$ average difference in SSI scores between satisfied and dissatisfied users. Orchik and Roddy (1980) compared the aided NU-6 and SSI scores of 14 subjects with mild to moderate sensorineural losses. Continuous discourse at $+20,0$ and $-20 \mathrm{~dB} \mathrm{MCR}(\mathrm{s})$ provided the competing noise. SSI scores were consistently better in all listening conditions than the NU-6 scores, and were also found to have significantly more variance than the NU-6 scores. The only exceptions to this variance were found in the performances at the most favorable signal to noise condition. The NU-6 aided benefit was greater at two of the three MCR(s) than that found with the SSI results. At 20,0 and $-20 \mathrm{~dB} \mathrm{MCR}$, the aided improvements were 19, 22 and 118, respectively, using the NU-6 lists, whereas the corresponding degrees of improvement with the SSI were 12,13 and $14 \%$, respectively. 
These small differences between the scores lead to the conclusion that the NU-6 and the SSI were "equally efficient - . to demonstrate aided benefit." The general conclusion of the study was that upon selecting an appropriate primary signal and corresponding $M C R$, any speech discrimination test can be used to evaluate a hearing aid's aided benefit and residual deficit.

Zerlin (1962) used a 30 second passage of conversational speech in conjunction with cafeteria noise creating $a+5 d B S / N$ ratio. The speech signal was recorded on two tracks of magnetic tape so that each track retained the signal as it was processed through six different hearing aids. The sensorineural hearing loss subjects were able to rapidly switch from track to track as they rated the intelligibility of two contrasted aids at a time. When little difference was discerned between aids, they rated their preferences as to the overall auditory comfort of the signals.

This paired comparison format has been utilized with a number of strategies. In a single elimination tournament the instrument that failed a single comparison was dropped from the running and that which passed was subsequently paired with another one that passed. By the process of matching successive winners against each other a final hearing aid was selected. 
By using the formula $(n-1)$, the comparison of eight different instruments required seven trials to select the "best" aid. The major assumption of this method assumed that the aid judged best would be chosen regardless of the specific seeding of the various competitors (Montgomery, et al. 1982). Montgomery, et al. (1982), however, found that when the eighth clearly dominant aid was not included, four of the remaining seven aids won the tournament roughly the same percentage of times depending on the initial seeding employed. It was, therefore, recommended that instruments with relatively homogenous characteristics should not be paired until later rounds of a tournament.

In the double elimination design, an aid had to be rejected after being compared with two different aids, one which was chosen in the first round and one which was rejected in its own first match. Montgomery et al. (1982) found more reliable results with the double elimination strategy. This procedure however, required 14 rather than seven different pairwise judgments $((n-1) 2)$. The seeding which included the eighth, clearly dominant aid, however was still more reliable than that seeding in which the eighth aid was not utilized.

The round robin tournament was the most complete paired comparison format because all individual aids were contrasted with each other. Such a design required $n(n-1) / 2$ pairings (Montgomery, 1982). Therefore, to involve eight 
instruments in a round robin tournament 28 different matches were required to determine the final outcome. Studebaker, et al. (1982) used a round robin tournament of eight different aids on subjects with normal hearing and with flat to sharply sloping high frequency losses. Their pairwise results were contrasted with NU-6 scores obtained under similar conditions. The hearing impaired groups' results were less consistent than those of the normal listeners, but nevertheless, they chose the aids that generally produced the best or better discrimination scores in the NU-6 testing.

Punch and Parker (1981) found poor agreement between phonemic identification scores using the Nonsense Syllable Test (to be discussed later) and pairwise comparisons when the pairwise comparisons were based on judgments of "sound quality." A relatively high overall agreement, however, was found between the phonemic identification scores and the paired comparison judgments when the judgments were based on "intelligibility." This later manner of instructing pairwise listeners was therefore deemed important.

Clinical demands placed a number of critical limitations on pairwise comparisons. Pascoe (1978) noted that great care must be taken to insure a close similarity between the recordings used in the comparisons and the actual in situ output of the corresponding instruments selected. He also pointed to the enormous task of 
constantly updating the sample of instruments needed to sufficiently represent the appropriate aids available to remedy the varied hearing losses encountered. Similarly, Ross (1978) cautioned clinicians regarding the almost insurmountable task involved in not only recording but also storing, rapidly retrieving and playing back the variety of responses available within each category of hearing aids.

On the opposite end of the spectrum, Bilger and Wang (1976) combined 16 consonants with three vowels to form a discrimination task involving 48 nonsense syllables. These syllables represented all of the permissible CV, VC combinations of English consonants as they appear with the vowels / $i$, e and $u /$. Their sensorineural subjects revealed mild to severe speech reception thresholds (SRT), as well as configurations that ranged from being flat, gradual sloping and high frequency in nature. Upon hearing each test syllable, the listeners, using a multiple choice format, circled that consonant of the 16 employed which they associated with the coarticulated vowel. The stimuli were presented at $40 \mathrm{~dB}$ SI unless the maximum output of the audiometer system was reached, or the subjects individually requested a lower level. This format was felt to maximize the contribution of acoustic factors that caused confusions and to correspondingly limit or eliminate potential linguistic factors. 
The consonant confusion matrices used to analyze the data yielded highly stable patterns of performance in individual subjects. It was noted that overall performance scores were not correlated with similar confusion patterns and could not be associated with specific audiometric configurations. Because of the complete nature of the multiple choice format, however, confusion patterns themselves were correlated with the three audiometric configurations described. On the basis of their confusion matrix results, Bilger and Wang (1976) were able to group their subjects into three general audiometric categories. Although their generalizations were not perfect, they did enjoy good cross validation by placing 10 out of 12 new subjects into the three confusion pattern groups on the basis of the audiometric data above.

Resnick, et al. (1975) developed a closed set discrimination task that was similar to that described by Bilger and Wang (1976). It consisted of $91 \mathrm{CV}$, VC items which were divided into 11 subtests and is known as the Nonsense-Syllable Test (NST). Dubno, et al. (1982) used the NST with subjects possessing mild to moderate sensorineural hearing losses. Again, flat, gradual sloping and steeper sloping audiometric configurations were represented. Together with other syllable recognition studies involving consonant confusion patterns they noted several general conclusions. Syllable recognition seemed to vary as a 
function of consonant manner and place of articulation. When an error was made, the substituted syllable usually consisted of the same manner of articulation but differed in place, the point of greatest constriction. The best performances on the NST were generally associated with gradually sloping configurations. Individuals with flat hearing losses were rated second in their performance accuracy. The poorest syllabic recognition was noted with those sharing high frequency losses. The NST materials were apparently sensitive to the effects of low frequency as well as high frequency impairments. As with Bilger and Wang's (1976) syllable test, individual consonant confusion patterns were more directly related to audiometric configurations than to overall performance levels (Dubno, et al., 1982).

In their work with nonsense syllables, Bilger and Wang (1976) found that the performance levels of their subjects improved when feedback regarding the nature of their errors was provided. Dubno, et al. (1982) agreed with them, and therefore, recommended that a closed set nonsense syllable test such as the NST could be beneficial when incorporated into an aural rehabilitation program. Dubno, et al. (1982) presented the NST eight different times to their subjects with mild to moderate sensorineural losses. The consistency of their responses was found to be highly reliable. The NST 
was subsequently recommended as a valuable tool in comparative hearing aid evaluations.

Feeney and Franks (1982) developed another syllabic consonant test called the Distinctive Features Difference test $(D F D) . / b, t, d, f, d z, k, p, s, S, t h, d, \theta$ and $v /$ were the 13 test item phonemes. Each was presented in the same intervocalic context /^bIl, ^tIl, etc./, and upon hearing each item, the listeners circled that phoneme of the above 13 which they thought they had heard. Their responses were evaluated on the basis of seven distinctive features. For each feature of a response that matched that of the primary signal, a point was received thus allowing for a total possible score of 91 . Four of the features were related to the tongue's position (high, back, anterior or coronal), one was concerned with whether or not the phoneme was continuant in manner, and the final two rated the sounds in terms of voicing (voiced - unvoiced) and vocal tract turbulence (stridency). This use of distinctive features was purported to add reliability by evaluating a large number of speech characteristics with a small number of stimuli. A S/N ratio of $+20 \mathrm{~dB}$ (noise intensity was $70 \mathrm{dBA}$ ) using pink noise was employed and has been found to be the condition that best approximated a 758 performance level. Normal listeners responded to CID $\mathrm{W}-22$ and DFD materials processed through a $.8 \mathrm{kHz}$ low pass filter. The distinctive feature scores of the DFD produced the smallest 
mean test-retest and standard deviation variance. No testretest difference for any subject exceeded $7 \%$ and only 58 of the subjects exceeded $5 \%$ in their score differences. Scoring the DFD by the percentage of phonemes correct yielded the next lowest test-retest difference but the largest standard deviation. The $\mathrm{w}-22$ results had the largest test-retest differences and second largest standard deviation. $72 \%$ of the subjects revealed test-retest differences in excess of 58 for both the phonemic DFD scores and the $\mathrm{w}-22$ evaluation.

When subjects with mild to moderate sensorineural losses received test-retests of the DFD (following six to nine practice trials), the smallest differences were again noted with distinctive feature analysis. Again, only 58 revealed score differences of from $5 \%$ to the maximum noted of 78 . Phonemic scoring found 558 of the subjects to have score differences ranging from $5 \frac{8}{8}$ to the $7 \%$ maximum. Feeney and Franks (1982) concluded that the DFD had definite potential as an efficient and sensitive speech discrimination test for hearing aid evaluations, and they found the closed set response format appropriate for unsophisticated or elderly clients.

With the advent of an increasing selection of hearing aid features and frequency responses, more sophisticated discrimination tests that can better define possible remedial variations have become necessary. Geffner and 
Donovan (1974) referred to a number of studies describing the inability of $\mathrm{w}-22$ word lists to differentiate mild and high frequency losses from normal listeners. 35 subjects with sensorineural losses beyond $2 \mathrm{kHz}$ were found to have mean scores of 94.68 despite their complaint of reduced understanding of speech in their daily environments. Maroonroge and Diefendorf (1984) noted that even the currently well-used NU-6 test lists lack the sensitivity sufficient to differentiate fine variances in discrimination ability, especially those needed for hearing aid evaluations. Harris, et al. (1960) found hearing deficits beyond 2 and $3 \mathrm{kHz}$ at a disadvantage in comprehending key words in multiple choice sentences when speed stress was applied to the speech signals. Chari, et al. (1977) found the intelligibility of filtered consonants to be maximized by a one-third octave band centered at $2 \mathrm{kHz}$, second highest for those centered beyond $2 \mathrm{kHz}$ and lowest in bands for frequencies below $2 \mathrm{kHz}$. Skinner (1980) found that all of his listeners with losses above $2 \mathrm{kHz}$ yielded the best performances when the speech energy from 2 to $4 \mathrm{kHz}$ was up to $15 \mathrm{~dB}$ above the energy of that from .5 to $1 \mathrm{kHz}$.

A number of studies have attempted to rate the contributions of different sounds to speech discrimination. Using multiple choice monosyllabic word items structured to permit the confusion of different vowels, Owens, et al. (1971) concluded that such vowel items are inadequate for 
discrimination testing. Even though the vowels were selected for maximum difficulty, the mean test scores were too high ( 21.1 percentage points above the $\mathrm{W}-22$ scores derived under like conditions).

Over a two year period, Owens and Schubert (1968) observed consonant phoneme errors made on a series of 100 word recorded lists. Fifteen subjects listened to list 1 and 20 subjects listened to the subsequent four recorded lists. The participants were selected without regard to hearing loss etiology and exhibited $W-22$ scores of 20-70\%. Each item consisted of a stimulus word and four multiple choice response foils. Since the foil stems were identical, an error was assumed to be attributable directly to the varied phoneme. 106 of the 413 words employed originated from Thorndike and Lorge's (1952) summary count of the "most frequently" used English words. Fifty-two were from the category labeled as the "next most frequently" occurring words. The rest were scattered along a frequency of usage continuum. Twenty-five were not tallied by Thorndike and Lorge (1952). A succession of lists was formed, each based on the results of studies involving previous lists. Only the first list had foils that mixed voiced with unvoiced consonants (Owens and Schubert, 1968).

The foils of List 1 varied by initial consonants only, and contained both voiced and unvoiced alternatives. Voiced phonemes were rarely confused for unvoiced ones and vice 
versa. The liquids $/ r /$ and $/ 1 /$ were seldom confused with other sounds just as the nasals $/ m, n$ and $\eta /$ were usually confused only with themselves.

List 2 tested sounds in the final position and List 3 involved initial position test sounds. Lists 4 and 5 refined the previous two by excluding words seldom missed and by including both initial and final position foils. Lists 2 through 5 provided a blank for each foil which the subjects were instructed to use only if the test stimulus did not sound at all like one of the four choices provided. On the average, however, the subjects, utilized the blank only once for every 100 items. This option was therefore dropped from subsequent lists during later studies. All lists were presented at $40 \mathrm{~dB}$ SL re: SRT via the standard TDH-39 earphones (Owens and Schubert, 1968).

Data from Lists 2 through 5 was tallied for each phoneme tested. The probability of error for each phoneme was determined by multiplying the number of times that the phoneme was used as a stimulus by the number of subjects (20) and dividing the total into the number of errors that occurred. Table $I$ indicates the resulting probabilities of error for each phoneme as they appeared in the initial and final position.

Final position errors occurred more often than initial position errors. A thorough confusion matrix analysis was provided by Owens and Schubert (1968). They found 
confusions of both place and manner for the unvoiced stimuli. The interclass substitutions for place and manner were even more prominent with the voiced stimuli. Foils that differed from the stimulus only in place or manner were the ones with the largest supply of reasonably difficult foils. They were considered the most efficient closed set test phonemes. It was found that liquids and nasals provided little information when used as target phonemes.

As they published results on the sixth of the seventh tests that lead to the development of the California Consonant Test (CCT), Schubert and Owens (1971) initiated a preliminary exploration of how the individual test item characteristics related to discrimination ability. 156 individuals with sensorineural losses and 27 normal hearing subjects were tested for the study. A severe low pass filter was used to process the items delivered to the normal ears. The combined mean $\mathrm{W}-22$ scores of both groups was 568 . Test Number 6 consisted of 125 of the over 400 multiplechoice foils used by Owens and Schubert (1968) in the first five lists. The items of the original lists that were considered too easy, too difficult or did not elicit at least two different error responses were excluded. Owens and Schubert (1977) assumed that Test 6 sufficiently ranked the tested subjects on a continuum of overall intelligibility related to the perception of 
everyday speech. It was therefore assumed to have face validity. The performances on individual items were not well correlated but were found, on the average, to be independent of each other. They were therefore believed to measure different aspects involved in understanding everyday speech. Exceptions were noted for the lingual dental fricatives and affricatives $/ \int$ and $d /$ in the final position only and $/ t \int, s$, and $z /$ in both positions. Performance on these sounds relied on place rather than manner distinctions. Noting these exceptions, it was warned that substantially shortening the test would reduce its overall face validity. The insufficient size of this study's sample was noted, however, making it difficult to confirm these conclusions regarding the irreducibility of the test. Owens, et al. (1972) discussed the relationship that phonemic errors have between pure tone configurations. The Test 6 data they analyzed included the results of 156 subjects with sensori-neural hearing loss, twenty-seven normal hearing subjects impaired with a $.78 \mathrm{kHz}$ low pass filter and five normal hearing subjects from the study by Schubert and Owens (1971) that received unfiltered signals. From the original sample of 156 hearing impaired subjects, three subgroups were established. Sixteen subjects had a flat audiometric configuration with no more than a fluctuation of $10 \mathrm{~dB}$ from .5 to $8 \mathrm{kHz} ; 18$ had mild sloping losses from .5 to $4 \mathrm{kHz}$ and 14 had sharply sloping 
configurations of at least $20 \mathrm{db} /$ octave from .5 through

$4 \mathrm{kHz}$.

TABLE I

PROBABILITIES OF PHONEMIC ERROR IN THE

CALIFORNIA CONSONANT TEST

(CCT)

FINAL POSITION

\begin{tabular}{|c|c|c|c|c|c|}
\hline Stimulus & $\begin{array}{l}\text { Total } \\
\text { Error/Trials }\end{array}$ & $\begin{array}{l}\text { Probability } \\
\text { of Error }\end{array}$ & Stimulus & $\begin{array}{l}\text { Total } \\
\text { Errors/Trials }\end{array}$ & $\begin{array}{l}\text { Probability } \\
\text { of Error }\end{array}$ \\
\hline $\mid \mathrm{p} /$ & $218 / 400$ & .55 & $|\mathrm{k}|$ & $117 / 260$ & .45 \\
\hline$|m|$ & $62 / 120$ & .52 & $\mid \mathrm{p} /$ & $154 / 360$ & .43 \\
\hline$|v|$ & $86 / 180$ & .48 & $|\mathbf{s}|$ & $141 / 360$ & .39 \\
\hline$|s|$ & $171 / 360$ & .48 & $\mid t 51$ & $99 / 280$ & .35 \\
\hline$|t| 1$ & $153 / 340$ & .45 & $|s|$ & $106 / 320$ & .33 \\
\hline $\mathrm{kk} /$ & $197 / 440$ & .45 & $\mathrm{~b} /$ & $59 / 180$ & .33 \\
\hline$/ \mathrm{b} /$ & $46 / 120$ & .38 & $\mid \theta /$ & $48 / 100$ & .31 \\
\hline$|f|$ & $99 / 280$ & .35 & $/ d /$ & $54 / 180$ & .30 \\
\hline$|t|$ & $167 / 480$ & .35 & $/ t /$ & $106 / 360$ & .29 \\
\hline$/ \mathrm{d} /$ & $65 / 200$ & .33 & $|d| 3 \mid$ & $36 / 140$ & .26 \\
\hline$|\theta|$ & $77 / 240$ & .32 & $\mathrm{~h} h$ & $68 / 300$ & .23 \\
\hline$|z|$ & $60 / 220$ & .27 & $|\mathbf{w}|$ & $21 / 120$ & .17 \\
\hline 151 & $60 / 260$ & .23 & $\lg /$ & $25 / 160$ & .16 \\
\hline /g & $35 / 160$ & .22 & $\mid \mathbf{f} /$ & $40 / 280$ & .14 \\
\hline$|\mathbf{r}|$ & $1 / 20$ & .05 & $|\mathrm{v}|$ & $15 / 140$ & .11 \\
\hline 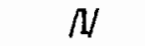 & $3 / 60$ & .05 & $|\mathbf{r}|$ & $10 / 180$ & .06 \\
\hline$/ \mathrm{m} /$ & $1 / 20$ & .05 & $N$ & $8 / 100$ & .08 \\
\hline$/ \mathrm{n} /$ & $2 / 60$ & .03 & $|z|$ & $12 / 20$ & .60 \\
\hline$|\eta|$ & $6 / 20$ & .30 & $|j|$ & $3 / 40$ & .08 \\
\hline & & & $\mid \mathrm{n} /$ & $9 / 40$ & .23 \\
\hline
\end{tabular}

\section{INITIAL POSITION}

45

43

39

.35

33

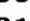

.30

.29

.26

.16

.14

.11

.06

.08

.60

.23

(Owens and schubert, 1968)

As with Lists 1-5, most of the words used in List 6 originated from Thorndike and Lorge's (1952) high frequency of use category. The liquids / $r$ and $1 /$ were eliminated because of the minimal number of errors previously associated with them (Owens and Schubert, 1968). /z, j and w/ were dropped because there were an insufficient number of 
similarly stemmed English CVCs that could provide alternates for the sounds within the chosen test format.

Table II compares the W-22 scores with those of Test 6 , and Figure 1 shows schematics of the real and contrived losses compared (Owens, et al., 1972). As indicated by their scores, the groups with the sharpest sloping real or contrived audiometric losses found Test 6 to be notably more difficult than the $\mathrm{w}-22$ recording. Test 6 was more sensitive to extreme high frequency losses.

TABLE II

MEAN W-22 AND TEST 6 PERCENTAGE SCORES FOR SEVERAL AUDIOMETRIC CONFIGURATIONS

\begin{tabular}{|c|c|c|c|}
\hline Group & $\begin{array}{ll} & \text { Number } \\
\text { P } & \text { Patients } \\
\end{array}$ & $\begin{array}{l}\text { W-22 } \\
\text { (List 4D) }\end{array}$ & Test 6 \\
\hline $\begin{array}{l}\text { Total } \\
\text { Flat Configuration } \\
\text { Mild Slope } \\
\text { Sharp slope } \\
\text { Normals with } 780 \mathrm{~Hz} \\
\text { low pass filter }\end{array}$ & $\begin{array}{r}156 \\
16 \\
18 \\
14 \\
27\end{array}$ & $\begin{array}{l}578 \\
518 \\
558 \\
658 \\
608\end{array}$ & $\begin{array}{l}608 \\
688 \\
618 \\
568 \\
468\end{array}$ \\
\hline
\end{tabular}

Tables III and IV list the probabilities of error for the individual test items according to the results by Owens, et al. (1972). These probabilities of error were calculated with the same formula used by Owens and Schubert (1968). The phonemes found to be most sensitive to high frequency losses were $/ s, f, t f, d z, t$, and $\theta /$ as listed in Table III. Errors of initial and final /s/ as well as initial /t and $\theta /$ had the highest correlation with losses above $2 \mathrm{kHz}$. 
Identification of $/ S, t /$ and $d /$ in both positions were associated with energy between 1 and $2 \mathrm{kHz}$ as only those individuals with losses commencing at $1 \mathrm{kHz}$ or below made errors with these sounds. Final / $t /$ and to a lesser degree, final $/ \theta /$ seemed more dependent on energy from .5 to $2 \mathrm{kHz}$. (Owens, et al., 1972).

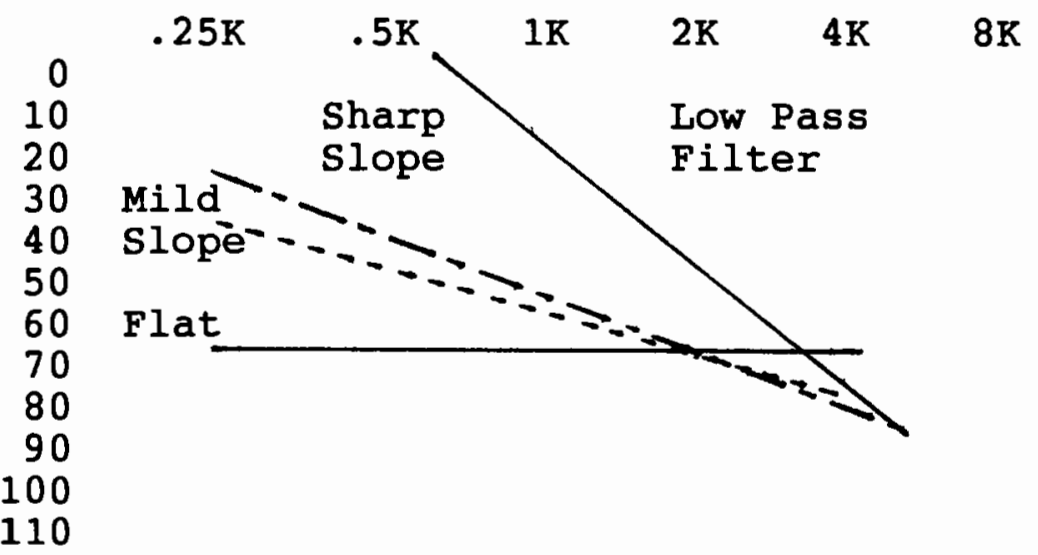

Figure 1. Schematics for selecting pure tone configurations in Owens and Schubert (1968).

For those sounds less sensitive to higher frequency components, as shown in Table IV, no real consistencies were revealed except for the final /b and $d /$ which had higher probabilities of errors once the high pitch loss configuration began at $1 \mathrm{kHz}$ or less. The small number of samplings for $/ g$, d and initial $\mathrm{z} /$ was a purported cause of their irregularities.

Owens, et al. (1972) tallied the frequency of substitutions made for different phonemes as they related to the following audiometric configurations: flat, flat with sharp drops beyond $2 \mathrm{kHz}$, gradual drops from .5 through 4 
$\mathrm{kHz}$, gradual decline beyond $1 \mathrm{kHz}$, sharp drop from .5 to 4 $\mathrm{kHz}$, sharp drop between 1 and $2 \mathrm{kHz}$ with higher frequency leveling and the impairment induced by a $.78 \mathrm{kHz}$ band pass filter employed on normals. Generally, only two or three substitutions were revealed for most phonemes regardless of the configurations involved, although five phonemes were perceived incorrectly as being three to eight different sounds. Few errors were made in regard to voicing, but many substitutions did reveal misperceptions based on the place of articulation. Confusions of affricatives, fricatives and stop plosives for each other were also found to be common (Owens, et al. 1972).

Sher and Owens (1974) analyzed the phonemic errors associated with sensorineural high tone losses commencing at $2 \mathrm{kHz}$ and with the effects on normal listeners subjected to $2.04 \mathrm{kHz}$ high pass filters. The seventh CVC test of the prementioned series by Owens and Schubert (1968) was employed for their analysis and was later called the California Consonant Test (CCT). As with the other studies using this series of tests that lead to the CCT, no background maskers were employed.

The number of times that each phoneme was used as the test stimulus is listed in Table $\mathrm{V}$. Voiceless phonemes received the greatest overall representation as the targeted phonemes as they comprised nearly half of the test in the final position and nearly a third of the test in the initial 
position. Initial and final voiced phonemes together comprised only about one fifth of the phonemes targeted. The CVCs were presented at $40 \mathrm{~dB}$ SL re SRT.

\section{TABLE III}

PROBABILITY OF ERROR ON PHONEMES SENSITIVE TO HIGH FREQUENCY LOSSES

\section{Configurations}

\begin{tabular}{|c|c|c|c|c|c|c|}
\hline $\begin{array}{l}\text { Phon } \\
\text { Posit }\end{array}$ & $\begin{array}{l}\text { eme } \\
\text { ion }\end{array}$ & $\begin{array}{l}\text { Flat .5- } \\
.8 \mathrm{kHz} \\
(\mathrm{N}=16) \\
\end{array}$ & $\begin{array}{l}\text { Flat to } \\
2 \mathrm{kHz} \\
\text { Then } \\
\text { Sharp Drop } \\
(\mathrm{N}=11)\end{array}$ & $\begin{array}{l}\text { Flat to } \\
1 \mathrm{kHz} \\
\text { Then } \\
\text { Sharp Drop } \\
(\mathrm{N}=19)\end{array}$ & $\begin{array}{l}\text { Sharp Drop } \\
.5-4 \mathrm{kHz} \\
(\mathrm{N}=14) \\
\end{array}$ & $\begin{array}{l}\text { Normals with } \\
.78 \mathrm{kHz} \\
\text { Low-Pass } \\
\text { Filter } \\
(\mathrm{N}=27) \\
\end{array}$ \\
\hline$|s|$ & $\begin{array}{l}\text { Final } \\
\text { Initial }\end{array}$ & $\begin{array}{l}0.24 \\
0.16\end{array}$ & $\begin{array}{l}0.68 \\
0.45\end{array}$ & $\begin{array}{l}0.67 \\
0.54\end{array}$ & $\begin{array}{l}0.56 \\
0.49\end{array}$ & $\begin{array}{l}0.70 \\
0.55\end{array}$ \\
\hline 151 & $\begin{array}{l}\text { Final } \\
\text { Initial }\end{array}$ & $\begin{array}{l}0.17 \\
0.08\end{array}$ & $\begin{array}{l}0.25 \\
0.06\end{array}$ & $\begin{array}{l}0.52 \\
0.58\end{array}$ & $\begin{array}{l}0.39 \\
0.52\end{array}$ & $\begin{array}{l}0.64 \\
0.69\end{array}$ \\
\hline$|t| 1 \mid$ & $\begin{array}{l}\text { Final } \\
\text { Initial }\end{array}$ & $\begin{array}{l}0.10 \\
0.09\end{array}$ & $\begin{array}{l}0.13 \\
0.05\end{array}$ & $\begin{array}{l}0.60 \\
0.43\end{array}$ & $\begin{array}{l}0.53 \\
0.40\end{array}$ & $\begin{array}{l}0.76 \\
0.60\end{array}$ \\
\hline |c|z| & $\begin{array}{l}\text { Final } \\
\text { Initial }\end{array}$ & $\begin{array}{l}0.10 \\
0.00\end{array}$ & $\begin{array}{l}0.11 \\
0.00\end{array}$ & $\begin{array}{l}0.57 \\
0.21\end{array}$ & $\begin{array}{l}0.51 \\
0.50\end{array}$ & $\begin{array}{l}0.64 \\
0.56\end{array}$ \\
\hline $\mid \mathrm{t} /$ & $\begin{array}{l}\text { Final } \\
\text { Initial }\end{array}$ & $\begin{array}{l}0.37 \\
0.04\end{array}$ & $\begin{array}{l}0.51 \\
0.38\end{array}$ & $\begin{array}{l}0.45 \\
0.46\end{array}$ & $\begin{array}{l}0.44 \\
0.42\end{array}$ & $\begin{array}{l}0.24 \\
0.59\end{array}$ \\
\hline$|\theta|$ & $\begin{array}{l}\text { Final } \\
\text { Initial }\end{array}$ & $\begin{array}{l}0.58 \\
0.22\end{array}$ & $\begin{array}{l}0.55 \\
0.43\end{array}$ & $\begin{array}{l}0.49 \\
0.65\end{array}$ & $\begin{array}{l}0.43 \\
0.64\end{array}$ & $\begin{array}{l}0.58 \\
0.55\end{array}$ \\
\hline
\end{tabular}

(Owens, et al., 1972)

The mean CCT scores were 72.58 and 75.48 for the sensorineural loss and high pass filtered groups, respectively. The high tone loss group was divided into two subgroups rated as having mild or sharp slopes. The first consisted of 13 subjects with a slope of $25 \mathrm{~dB}$ HL per octave or less. The average slope was $17 \mathrm{~dB} \mathrm{HL}$ from 2 to $3 \mathrm{kHz}$ and 
$14 \mathrm{~dB} \mathrm{HL}$ from 3 to $4 \mathrm{kHz}$. This mild class of listeners had slopes roughly equivalent to the $15 \mathrm{~dB} /$ half octave slopes of the normal, filtered group. The steep sloping groups $(n=22)$ dropped $30 \mathrm{~dB}$ or more from 2 to $3 \mathrm{kHz}$ averaging $43 \mathrm{~dB} \mathrm{HL}$ and dropped an average of $11 \mathrm{~dB} \mathrm{HL}$ from 3 to $4 \mathrm{kHz}$. A statistical analysis revealed a significant difference between the mild and sharp sloping groups ( $F=3.28, d f=2.60$, $\mathrm{p}<.05)$. No significant difference was noted between the normals subjected to high pass filtering and the mild sloping loss group $(t=2.29, \mathrm{df}=48, \mathrm{p}<.025)$ (Sher and Owens, 1974).

The probabilities of error that were determined are indicated in Table VI. /b/ had the highest probability of error of the initial sounds but since it was only tested once, an unexplained artifact was suspected. In their order from greatest to least, the other initial sounds with a probability of error greater than . 1 were $/ s, 0, k, t, p$, and $d /$. The final sound probabilities of error greater than .1 in descending order were $/ s, z, \theta, b, p, t, f, k, t), v, d z$ , and $\int /$. The preponderance of final position errors is consistent with the combined results of Lists $1,2,3$ and 4 as determined by Owens and Schubert (1968) and Owens, et al. $(1972) \cdot$ 
TABLE IV

PROBABILITY OF ERROR ON PHONEMES LESS SENSITIVE TO HIGH PREQUENCY LOSSES

\section{Configurations}

\begin{tabular}{|c|c|c|c|c|c|c|}
\hline $\begin{array}{l}\text { Pho } \\
\text { Pos }\end{array}$ & $\begin{array}{l}\text { eme } \\
\text { ion }\end{array}$ & $\begin{array}{l}\text { Flat .5- } \\
.8 \mathrm{kHz} \\
(\mathrm{N}=16) \\
\end{array}$ & $\begin{array}{l}\text { Flat to } \\
2 \mathrm{kHz} \\
\text { Then } \\
\text { Sharp Drop } \\
(\mathrm{N}=11)\end{array}$ & $\begin{array}{l}\text { Flat to } \\
1 \mathrm{kHz} \\
\text { Then } \\
\text { Sharp Drop } \\
(\mathrm{N}=19)\end{array}$ & $\begin{array}{l}\text { Sharp Drop } \\
.5-4 \mathrm{kHz} \\
(\mathrm{N}=14) \\
\end{array}$ & $\begin{array}{l}\text { Normals with } \\
.78 \mathrm{kHz} \\
\text { Low-Pass } \\
\text { Filter } \\
(\mathrm{N}=27) \\
\end{array}$ \\
\hline$/ \mathrm{p} /$ & Final & 0.48 & 0.48 & 0.60 & 0.61 & 0.62 \\
\hline & Initial & 0.42 & 0.44 & 0.46 & 0.36 & 0.37 \\
\hline$/ \mathrm{k} /$ & Final & 0.50 & 0.58 & 0.56 & 0.48 & 0.62 \\
\hline & Initial & 0.30 & 0.42 & 0.49 & 0.42 & 0.56 \\
\hline /f/ & Final & 0.43 & 0.45 & 0.39 & 0.33 & 0.42 \\
\hline & Initial & 0.22 & 0.18 & 0.24 & 0.07 & 0.19 \\
\hline$/ \mathrm{b} /$ & Final & 0.62 & 0.62 & 0.50 & 0.32 & 0.39 \\
\hline & Initial & 0.34 & 0.41 & 0.32 & 0.36 & 0.24 \\
\hline$/ d /$ & Final & 0.56 & 0.47 & 0.34 & 0.14 & 0.21 \\
\hline & Initial & 0.53 & 0.59 & 0.34 & 0.43 & 0.48 \\
\hline |g/ & $\begin{array}{l}\text { Final } \\
\text { Only }\end{array}$ & 0.06 & 0.36 & 0.11 & 0.14 & 0.19 \\
\hline$|z|$ & Final & 0.45 & 0.68 & 0.58 & 0.57 & 0.65 \\
\hline & Initial & 0.37 & 0.64 & 0.32 & 0.64 & 0.44 \\
\hline$/ \mathrm{v} /$ & $\begin{array}{l}\text { Final } \\
\text { Only }\end{array}$ & 0.44 & 0.52 & 0.46 & 0.33 & 0.54 \\
\hline $\mid$ & $\begin{array}{l}\text { Initial } \\
\text { Only }\end{array}$ & 0.81 & 0.73 & 0.84 & 0.79 & 0.56 \\
\hline$/ \mathrm{h} /$ & $\begin{array}{l}\text { Initial } \\
\text { Only }\end{array}$ & 0.13 & 0.09 & 0.07 & 0.02 & 0.00 \\
\hline
\end{tabular}


TABLE $\mathbf{v}$

\section{QUANTITIES OF TEST PHONEMES IN THE}

CALIFORNIA CONSONANT TEST

(CCT)

$\begin{array}{llrl}\text { Phoneme } & \text { Initial } & \text { Final } & \text { Total } \\ \text { Voiceless } & & & \\ \mid \mathrm{p} / & 4 & 10 & 14 \\ \mid \mathrm{t} / & 6 & 5 & 11 \\ \mid \mathrm{k} / & 6 & 6 & 12 \\ |\mathrm{t} /| & 4 & 8 & 12 \\ \mid \mathrm{s} / & 6 & 10 & 16 \\ \left|\int\right| & 3 & 3 & 6 \\ \mid \mathrm{f} / & 1 & 4 & 5 \\ \mid \mathrm{I} / & \frac{2}{32} & \frac{1}{47} & \frac{3}{79}\end{array}$

Voiced

$\begin{array}{lccc}\mid \mathrm{b} / & 1 & 2 & 3 \\ \mid \mathrm{d} / & 2 & - & 2 \\ \mid \mathrm{g} / & - & 1 & 1 \\ \mid \mathrm{d} / & 1 & 5 & 6 \\ |\mathrm{z}| & - & 4 & 4 \\ \mid \mathrm{v} / & \frac{5}{4} & \frac{5}{17} & \frac{5}{21}\end{array}$

Total

36

64

100

(Sher and Owens, 1974)

The target phonemes of the CCT found to be the most difficult for the high tone loss group were $/ p, t, k, s, \theta$, and $\mathrm{b} /$ in both the initial and final positions, /d/ in only the initial position and $/ t\}, \int, f, d z, z$ and $v /$ in only the final position. Little difficulty was noted with $/ t \int, \int, f$ and $g /$ in the initial position and /g/ in the final position (Sher and Owens, 1974). 
Sher and Owens (1974) found that in the initial position, with the exception of $/ v /$ for $/ b /$, voiced and unvoiced stops were substituted for other similarly voiced and unvoiced stops just as voiced and unvoiced fricatives were substituted for other respectively voiced and unvoiced fricatives. Usually, only one phoneme was mistaken for another phoneme. Two or more substitutions were made for each of the final position phonemes. Substitutions of fricatives and/or stops were perceived for other fricatives, stops and/or affricatives. Voicing errors again were not revealed. Except errors for $/ b /$, the initial position errors were of the same manner as the stimuli, but that was not always true for errors associated with final position phonemes.

In their discussion of the series of studies that led to the CCT, Owens and Schubert (1977) noted that different recordings of the same word lists often yielded variant responses. This was regardless of whether or not the same speaker made each recording. In studies of the original Iists $1-6$, the stimuli were presented twice each to insure the listener's attention. The procedure, however, did not lend itself to improved performances but only consumed extra time. It was therefore eliminated when they published results of three experiments involving the seventh and final product known as the California Consonant Test. Two scramblings of the same recording were created. 
TABLE VI

\section{PROBABILITY OF ERROR FOR CCT TARGET PHONEMES}

\begin{tabular}{clll}
$\begin{array}{c}\text { Phoneme } \\
\text { Initial Position }\end{array}$ & $\begin{array}{l}\text { High Tone } \\
\text { Loss }\end{array}$ & $\begin{array}{l}\text { Normal } \\
\text { Filtered }\end{array}$ & $\begin{array}{c}\text { Number Of } \\
\text { Items }\end{array}$ \\
\cline { 2 - 3 }$/ \mathrm{b} /$ & .53 & .57 & 1 \\
$/ \mathrm{s} /$ & .27 & .28 & 6 \\
$/ \mathrm{O} /$ & .26 & .09 & 2 \\
$/ \mathrm{k} /$ & .21 & .22 & 6 \\
$/ \mathrm{t} /$ & .19 & .27 & 6 \\
$/ \mathrm{p} /$ & .17 & .07 & 4 \\
$/ \mathrm{d} /$ & .11 & .07 & 2 \\
$/ \mathrm{f} /$ & .08 & .04 & 1 \\
$/ /$ & .07 & .07 & 3 \\
$/ \mathrm{t} /$ & .06 & .04 & 4 \\
$/ \mathrm{d} /$ & .03 & .00 & 1
\end{tabular}

Final Position

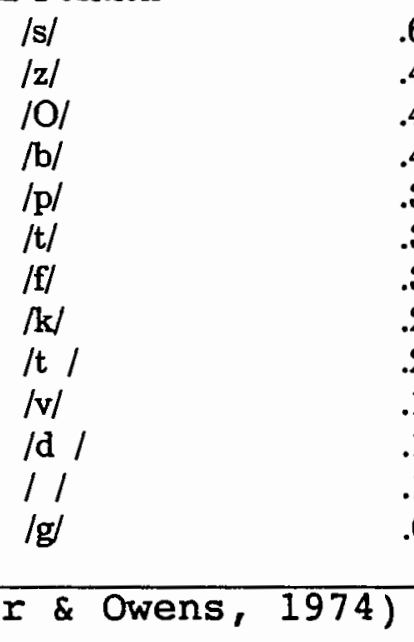

.61

.47

.44

.40

.37

.36

.30

.24

.24

.18

.13

.12

.03
.63

.51

.25

.30

.31

.43

.13

.13

.24

.12

.08

.12

.00
10

4

1

2

10

5

4

6

8

5

5

3

1

(Sher \& Owens, 1974)

In the first of their experiments on the CCT, Owens and Schubert (1977) rearranged the responses of 100 subjects into two 50 word halves which were distributed as equally as possible in phonetic composition. All subjects were reported to have sensorineural losses including high tone deficits. A Pearson product-moment correlation of .87 was reported between the two halves. Such a correlation was 
deemed too low to equate the half-list arrangements. The 100 items took approximately 15 minutes to administer.

In the second of the experiments, the carrier phrase of the speaker was shortened as were the tasks required of the listeners. The sample of subjects was increased to 294. The 100 item completion time was reduced to 12 minutes. Of 56 subjects who took the test twice in succession, the testretest correlation was .91 with no indication of adverse effects due to learning or fatigue. The responses of most subjects were "well within 10 points" of their own performances from trial to trial, but an occasional listener showed a variance of 18 points. Some subjects, however, felt rushed during the trials, others noted changes in their listening set in mid test and others listened at contrasting times with eyes closed and open. These factors were felt to effect the above noted variations in test-retest responses. Lower means were again noted for individuals with high tone loss configurations. A low correlation of $(-.40)$ was noted of CCT scores and flat audiometric configurations.

In experiment three, subject response tasks were further simplified and six practice items were presented to allow the listeners to develop a response rhythm for the task. The sample size consisted of 50 subjects. Some hoped-for improvements in variance were noted. A high test-retest correlation of .96 was found for the 100 word version. Pearson product moment test-retest correlations for the 
paired 50 word lists were as follows: 1a-2a (same items), $.92 ; 1 b-2 b$ (same items), .93; 1a-1b,.88;2a-2b,.91;1a$2 b, .89$; and $1 b-2 a, .89$. These results were said to indicate that for two-thirds of the subjects tested with any half list, no greater than 4.4 errors would be expected. The greatest variances noted between successive tests was six points. A 108 confidence interval or a seven point difference between aided scores was, therefore, recommended as the criterion for rejecting a hearing aid during a remedial evaluation using half lists.

Schwartz and Surr (1979) also examined the CCT in several ways. In their first experiment, the results of 12 normal listeners and 12 with high frequency impairments beyond $1 \mathrm{kHz}$ (with slopes averaging $28 \mathrm{~dB} /$ octave) were compared. Performance-intensity (P-I) functions for each of the four 50 word subforms were determined at sensation levels of $0,8,16,24,32,40$ and $50 \mathrm{~dB}$ SL. For the normal listeners, the linear function of the CCT results was 1.68 per $\mathrm{dB}$ SL with the asymptote beginning at $50 \mathrm{~dB}$ SL. The NU6 results revealed a considerably steeper PI function of 5.18 per $\mathrm{dB}$ SI and a commencement of the asymptote at $32 \mathrm{~dB}$ SL. For the individuals with the high frequency losses the CCT PI function reached the asymptote at roughly the same level with a slope of 1.68 per $d B$ SL. The transition to non-linearity occurred at a lower mean word identification 
score, again proving itself particularly sensitive to high frequency deficits.

In their second experiment, Schwartz and Surr (1979) compared results of CCT recordings, presented at $50 \mathrm{~dB}$ SL in sound field, with those results of NU-6 lists I-IV Form B, presented at $40 \mathrm{~dB} \mathrm{SL}$. These levels were chosen to insure presentations within the respective PI function plateaus. All 60 subjects had hearing losses similar to those described for the first experiment. The range of scores for the CCT was from 40 to 908 with a $68 \%$ mean. 338 of the subjects had scores between 80 and 908 . For the NU-6 recordings, a range of 40-98\% and a mean of $87 \%$ was noted. 538 of the scores exceeded 908. The distribution of scores revealed the ССТ recordings were more sensitive to the high frequency losses than were the NU-6 recordings.

In their third experiment, full versus half list results of 10 additional subjects, all with the same high frequency loss configurations, were compared. For List 1, $30 \%$ of the listeners demonstrated differences of $10 \%$ or greater between halves. For List 2, 608 of the subjects displayed differences of $10 \%$ or more. The dispersion among the half list results, especially for List 2, were large enough that Owens and Schubert (1977) discouraged the clinical use of the 50 word lists.

Danhauer and Leppler (1979) studied the effects of four noise competitors on CCT performances of 35 normal 
listeners. "Babble noise" produced by four talkers (FT), and nine talkers (called Bowling Green Multi-talker Noise, BGMTN) made up two of the competing signals employed.

cocktail party noise (CPN) and electronically generated white noise were the other two competitors utilized. Each masker was presented at a continuum of seven different signal to noise ratios $(-3$ or $0 \mathrm{~dB}$ to $+30 \mathrm{~dB}$ ) intended to elicit proportionate scores ranging from the chance performance level of 25-308 (Owens and Schubert, 1977) to that of maximum discrimination. The CCT items were presented at $45 \mathrm{~dB}$ SL.

Danhauer and Leppler (1979) found the CCT scores revealed a linear function as the $\mathrm{S}: \mathrm{N}$ ratios became progressively larger. No significant difference was noted between the multi-talker competitors (FT and BGMTN), just as there were no differences with the white and cocktail party noises. There was, however, a statistical difference noted between these paired maskers, at the $0 \mathrm{~dB} \operatorname{MCR}(t(B)=3.03$, $d f=112, x=0.05)$. Significant differences were also noted for the FT and BGMTN competitors in comparison to the CPN competitor at $+5 \mathrm{~dB} S / \mathrm{N}(t(B)=3.03, \mathrm{df}=112, \mathrm{x}=.05)$. The multi-talker noises were more effective in both cases, and it was hypothetically reasoned that the cause may be due to perceptional rather than peripheral phenomenon.

Surr and Schwartz (1980) studied the performance effects of 12-talker babble on CCT scores of 40 normal and 30 high 
frequency loss listeners. The mean audiometric

configuration represented by the abnormal subjects exhibited a mild to moderate deficit beyond $1000 \mathrm{~Hz}$. The CCT was presented at a $0^{\circ}$ azimuth, both in quiet and with competing noise presented at a $180^{\circ}$ azimuth. The $\operatorname{MCR}(\mathrm{s})$ employed were $+12,6$, and $0 \mathrm{~dB}$ for both groups with the addition of $-6 \mathrm{~dB}$ for the normal hearing subjects. The normal ears exhibited mean performances of $938,888,808$ and 668 at the respective $\operatorname{MCR}(s)$. The abnormal ears revealed performances that paralleled those of the normal subjects but with scores reduced by approximately 30\%. As in Danhauer and Leppler (1979), the noise was found to have a generally linear detriment on normal listener performance levels, although a notably greater decline was found with the normals as the MCR dipped to $-6 \mathrm{~dB}$. The dispersion of scores was constant at all MCRs for the hearing loss group but revealed significant increases in the standard deviations for the normal hearing group as test conditions became more difficult with the addition of noise and generally, as performances dropped toward the 50 percent level. The increased variability associated with adding noise to CCT presentations made Surr and Schwartz (1980) recommend against the use of the CCT with a competing signal.

In their study, they found the test-retest reliability for the $3 \mathrm{MCR}(\mathrm{s})$ was generally moderate with Pearson Product Moment correlations coefficients of $.77, .91$, and .79 at 
$+12,+6$, and $0 \mathrm{~dB}$, respectively. The higher correlation noted for $+6 \mathrm{~dB}$ was felt to be due to variances encountered in a small sample size. According to cumulative frequency distributions of test-retest difference scores, the chance of a $6 \%$ difference upon retest using full and half CCT lists was found to be 60 and 558, 90 and 458 and 60 and $45 \%$ for $12 \mathrm{~dB}, 6 \mathrm{~dB}$ and $0 \mathrm{~dB} \mathrm{MCR}(\mathrm{s})$, respectively. Overall, a $10 \%$ difference was needed between full list scores for a $95 \%$ level of confidence versus a necessary 148 difference required between half list scores. The greater differences in test retest scores of $\mathrm{CCT}$ half lists recommended against their use in clinical settings (Surr and Schwartz, 1980).

Schwartz, et al. (1979) used the CCT, NU-6 and a 160 item CV nonsense syllable test in quiet and in 12 speaker babble noise to compare aided and unaided performance of 10 subjects with mild to moderate high frequency losses.

The 8 phonemes in the nonsense syllable test were the same voiceless phonemes that comprised 798 of the phonemes targeted in the CCT, and listed in Table $\mathrm{V}$ as those most sensitive to high frequency losses. Nine of the 10 subject's own aids used in the study were the same conventional high frequency emphasis instrument and all 10 were separately aided with an extended high pass oticon EllHC. Sound field measurements displayed a mean of $4 \mathrm{~dB}$ more functional gain through $1.3 \mathrm{kHz}$ with the conventional high pass aids over the extended high pass aid. The 
extended high pass Oticon instrument, however, showed the greatest mean functional gain difference over the mean of the conventional high pass aids at $2 \mathrm{kHz}$ and beyond. This difference increased as a function of frequency to a maximum of approximately $20 \mathrm{~dB}$ at $5 \mathrm{kHz}$.

Their mean in quiet and in noise scores for all three tests and test conditions are provided in Table VII. The corresponding amounts of aided improvement are depicted in Table VIII. Statistical analysis of variance revealed no significant differences between aided results in the quiet condition. The NU-6, CCT and CV tests, however, did reveal significant improvement in noise with the extended high pass aid over the conventional high frequency instrument.

Taking into account the conclusions of Schwartz and Surr (1979) and Surr and Schwartz (1980) in which they advised against the use of CCT half lists, Tecca and Binnie (1982) applied a modified broadband noise and a simple up-down (SUD) procedure to the CCT in order to reduce the clinical time required to obtain reliable results form it. The speech signals were presented at $80 \mathrm{~dB}$ SPI when the subjects were aided with the broadband Widex $A 8+T$ and at $75 \mathrm{db}$ SPL when they were aided with the high pass Widex A6T. The noise was varied in $2 \mathrm{~dB}$ increments according to the same SUD procedures used with spondees to obtain speech reception thresholds (SRT's). This was done in order to estimate which noise level would yield a $50 \%$ performance on the CCT 
with each aid for each subject. Full list $\operatorname{CCT}(s)$ were then presented in order to determine the accuracy of the SUD application in each case. The mean signal to noise ratios and their respective full list scores are listed in Table IX. Analysis of variance for repeated measures (ANOVA; Winer, 1971) revealed no significant differences between the full list CCT scores. This suggested that the SUD modification of the CCT could accurately predict the noise level needed to yield a 50 score.

The signal to noise levels obtained with each instrument using the adaptive procedure were found to significantly differ, indicating that the SUD modified CCT, using noise, had potential applications in hearing and evaluations. This abbreviated version of the test required only about three minutes, a notable clinical improvement over the 12 minutes needed for a full list CCT presentation.

Surr and Schwartz (1980) concluded that the use of multitalker noise was ineffective in improving the CCT's ability to reveal significant differences between performances of individuals with high frequency losses. In contrast, Schwartz, et al. (1979) found that the CCT along with the NU-6 and a nonsense syllable test employing the most commonly used phonemes of the CCT could not differentiate aided performances in quiet but that they could if 12 talker speech babble was applied. With their normal hearing subjects, Tecca and Binnie (1982) found that 
an abbreviated presentation of the CCT with competing broadband noise showed promise in comparing aided performances by estimating which MCR for each aid would yield a 508 discrimination score.

\section{TABLE VII}

SOUND FIELD DISCRIMINATION RESULTS OF HIGH FREQUENCY IMPAIRED SUBJECTS

TEST CONDITION

Quiet Unaided

Mean

$\mathrm{SD}$

13.0

89.2

7.0

SD

High Pass Aid

Mean

$\mathrm{SD}$

89.8

12.0

68.2

16.0

71.6

17.0
SD

Mean

$\mathrm{SD}$

Own Aid

Mean

High Pass Aid

Mean

SD
80.0

15.0
$\underline{\mathrm{CCT}}$

67.4

21.0

74.2

18.0

78.4

18.0

84.6

14.0

75.8

18.0

86.9

13.0
49.8

16.0

56.0

28.0

52.6

14.0

63.1

21.0

61.2

18.0
72.5

17.0

(Schwartz, et al. 1979)

The CCT clearly has been found to be sensitive to real and contrived high frequency hearing losses beyond 1 and 2 kHz. But how effective is it in performing comparative hearing aid evaluations and under which conditions is it most effective? Is the CCT, designed as it is to be more 
sensitive to high frequency impairments, a better tool for evaluating hearing aids on subjects with high frequency losses than the more clinically used NU-6? To examine these questions as they particularly apply to precipitous high frequency losses, the study described in the following chapter was designed.

\section{TABLE VIII}

\section{MEAN AIDED IMPROVEMENT IN DISCRIMINATION SCORES}

OF HIGH FREQUENCY IMPAIRED SUBJECTS

\begin{tabular}{llrrr} 
TEST & CONDITION & NU-6 & CCT & CV \\
Noise & Own Aid & 3.4 & 2.8 & 7.1 \\
& High-Pass Aid & 11.8 & 11.4 & 16.5 \\
\multirow{2}{*}{ Quiet } & Own Aid & 3.8 & 6.8 & 11.1 \\
& High-Pass Aid & 4.4 & 11.0 & 8.8
\end{tabular}

(Schwartz, et al. 1979)

\section{TABLE IX}

MEAN AIDED RESULTS AND STANDARD DEVIATIONS FOR SUD ESTIMATED S/N(S) THAT WOULD YIELD $50 \%$ CCT

SCORES AND CCT SCORES OBTAINED AT THE RESPECTIVE S/N(S)

\section{Instrument}

Widex $\mathrm{A} 8+\mathrm{T}$

Widex A6T

(Tecca and Binnie, 1982)
$\mathrm{CCT}$

S.D.

Intelligibility\%

S.D.

5.1

43.6

7.6

2.3

50.4

10.3 


\section{CHAPTER III}

\section{METHODS}

\section{SUBJECTS}

Two studies were conducted. To be included, all of the participants needed normal thresholds in one ear (to be used as the test ear) of $20 \mathrm{~dB}$ or less through $1 \mathrm{kHz}$ and $50 \mathrm{~dB}$ or greater at each frequency from 2 through $6 \mathrm{kHz}$ (re ANSI S.36 1969). They also needed to have no middle ear problems which would be revealed by an audiometric pure tone airbone gap or abnormal tympanograms. All subjects were experienced hearing aid users for at least six months and in current possession of at least one instrument. They were drawn from a pool of individuals who had been evaluated at one of three clinics in the Portland area and had been shown to reveal the above defined audiometric configuration.

A total of 13 subjects, one of them female, participated in these studies. The first study involved 10 people, and the second involved 11 people. Eight of the 13, including the female, were included in both studies. The 10 subjects in the first study ranged in age from 47 to 87 years with a mean of 67.3 years. The 11 subjects evaluated in the second study ranged in age from 41 to 87 years with a mean of 65.6 years. 


\section{INSTRUMENTATION}

Immittance tests were performed with a Teledyne Avionics TA-3D impedance bridge and recorded by a Teledyne Avionics TA-3P tympanogram plotter or by a SAICO SI-22 automatic impedance audiometer. The spondees used during the audiologic evaluation and during free field adjustments were routed through a Maico MA-24B audiometer from a Technics RS263AUS cassette tape recorder. The NU-6 cassette recordings were similarly routed through the Maico audiometer via the same recorder. The CCT recordings were played on a Sony reel to reel tape recorder at $7 \frac{1}{2}$ ips speed. The loud speakers employed in all sound field tests were in accordance with ANSI standards S.36-1969. Testing was conducted in a double walled Industrial Acoustics 1204 acoustic suite.

Electroacoustic characteristics of the aids were made in accordance with ANSI 3.22-1987 standards using a Frye Electronics FP 20 hearing aid analyzer. The actual frequency responses within the ear canals of the test ears were measured with an HA 2000 Spectrograph by American Electromedics Corporation. Using that equipment, insertion gain measurements, via the substitution method (Flores, 1988), compared the unaided natural ear canal resonances with those generated by each of the two hearing aids. A Bosch Star 66F $\mathrm{H}$, setting $\mathrm{H}_{2}$, and a Unitron UE $10 \mathrm{H}$, setting $H$, were used on each subject. Each aid was coupled to the 
patient's test ear with a custom skeleton lucite ear mold with a single parallel vent. The diameter varied in accordance with each subject's acoustic needs. Number 12 standard ear mold tubing was used with an internal diameter of .085 inches and an external diameter of .125 inches.

The audiometer was calibrated at the beginning of the study and at its conclusion. The sound field system was calibrated using broadband noise at the beginning of each day of sound field testing as was a biologic check of the audiologic system.

\section{PROCEDURES}

All participants were seen for at least two sessions at the Portland State University audiologic suite. Eight were seen for three sessions. Otoscopic inspection and immittance testing were performed during each session to help insure against any significant middle ear impairment. Testing included tympanometry and acoustic reflex testing at $.5,1$ and $2 \mathrm{kHz}$ or with broadband noise or both.

On the first day of testing all subjects received an audiologic evaluation. Air conducted pure tone thresholds were obtained for the octaves and half octaves .25, .5, 1 , $2,3,4,6$ and $8 \mathrm{kHz}$. Bone conducted thresholds were similarly obtained excluding 6 and $8 \mathrm{kHz}$. Speech reception thresholds and speech discrimination scores using NU-6 records (Form A, lists I and II) were obtained with 
headphones. Normal middle ear functions were confirmed with tympanometry and with positive acoustic reflex thresholds at or below normal sensation levels using pure tones and/or white noise. Candidates whose hearing in at least one ear met the criteria for the study had an impression made of the test ear. A custom, skeleton, singly vented ear mold was then made for each subject.

Both the Bosch Star $66 \mathrm{~F} \mathrm{H}$ and the Unitron UE $10 \mathrm{H}$ were coupled to each of the participants' custom ear molds and the vent diameters were adjusted, when necessary, to insure that reserve gain was available. If reserve gain was not available before acoustic feedback was detected, the vent size was reduced with variable vent plugs. If it was possible to turn both aids to their full on gain or near their full on gain positions, without feedback, the vent diameter was enlarged slightly and/or the canal tips length was reduced. This was to allow for the effective reduction of the acoustic output at frequencies below $800 \mathrm{~Hz}$.

Subjects were seated in the test booth with their heads at the $0^{\circ}$ azimuth, one meter from the speaker. Each hearing aid was adjusted to its most comfortable gain setting while recorded spondees were presented at $70 \mathrm{~dB}$ SPL. While noting the subsequent volume control position, the high frequency average of each aid was then recorded using a hearing aid analyzer and a 2cc coupler. In that way, if the volume 
control was accidentally changed, it could be returned to the same position for all test conditions.

The sound field HAE(s) then commenced. In each of the three conditions one 50 word NU-6 and one 100 word CCT list was presented at $70 \mathrm{~dB}$ SPL at a $0^{\circ}$ azimuth via a loudspeaker. Competing speech babble was presented from the same speaker at $60 \mathrm{~dB}$ SPL ( $+10 \mathrm{~s}: \mathrm{N}$ ratio) for those in the first study and there was no competing noise for those in the second study. It took approximately seven minutes to complete each 50 word NU-6 list. Each 100 word CCT recording took approximately 12 minutes. Actual test time for the discrimination tasks therefore rarely exceeded one hour per session for each subject. Subjects were allowed to take breaks following any completed recording.

All subjects evaluated in noise were tested in the unaided condition before being aided as were all subjects evaluated in quiet. Seven of the eight subjects that were included in both investigations listened to the stimuli in noise during the second session and in quiet during the third session. Due to scheduling complications, the other subject evaluated in both conditions only listened to unaided stimuli in the second session, in noise first, then in quiet. Aided presentations occurred during the third session, first in noise then in quiet.

In order to minimize learning effects and the effects of fatigue each CCT presentation was interspaced in time from 
other CCT tests by the presentation of an NU-6 recording. NU-6 lists were likewise spaced from each other by an intervening CCT list.

The order of the NU-6 and CCT lists were counterbalanced across subjects. Since there were four NU-6 lists in Form B, no subject of either group heard the same list during the same session. There were only two CCT lists, but their uses were alternated and spaced by time and intervening tasks involving the other CCT list and at least one, and sometimes two, NU-6 lists. The NU-6 and CCT lists were also counterbalanced across subjects to limit the number of times that any specific list was used first, second or third during the various sessions. Likewise, the order of presentation of the hearing aids was alternated so that neither the Bosch nor the Unitron instrument gained a consistent advantage of being predominately the first or last aid evaluated in the various sessions.

Following the comparative hearing aid evaluations, in Situ dB SPL readings (using the HA 2000 spectrograph by Acoustimed) were obtained for the test ear of seven subjects in each group, five of which were included in both studies. Unaided measurements were made with the probe tube alone extended into the test canal. With the Unitron and Bosch hearing aids adjusted to each subject's most comfortable gain setting, aided probe readings were made for each hearing aid. 


\section{CHAPTER IV}

\section{RESULTS AND DISCUSSION}

\section{RESULTS}

The mean thresholds for the subjects tested in noise and in quiet are presented in Tables $\mathrm{X}$ and $\mathrm{XI}$, respectively. Both groups revealed normal hearing through $1 \mathrm{kHz}$ with a precipitous loss in hearing commencing at $2 \mathrm{kHz}$. The mean speech reception thresholds were $20.5 \mathrm{~dB} \mathrm{HL}$ for those evaluated in noise and $19.5 \mathrm{~dB}$ HL for those evaluated in quiet. Mean most comfortable levels (MCL) for speech were $61.5 \mathrm{~dB}$ HL and $62.3 \mathrm{~dB} \mathrm{HL}$. Using TDH-39 headphones, the mean of the discrimination scores at the MCL(s) (NU-6, Form $B$, List 1-4) for those who received $\operatorname{HAE}(5)$ in noise was 76.8 and for those who received $\operatorname{HAE}(s)$ in quiet, it was 78.9 . These scores are included with their respective standard deviations and ranges in Table XII.

The 2cc coupler frequency responses of the two instruments used (the Bosch Star $66 \mathrm{~F} \mathrm{H}$ and the Unitron UE 10-H) are shown in Figure 2 as measured by the Fonix F20. The input level at each frequency was $60 \mathrm{~dB}$ SPL. To conduct these measurements the volume controls were adjusted to yield an $84 \mathrm{~dB}$ high frequency average with the Unitron instrument and an $85 \mathrm{~dB}$ high frequency average for the Bosch 
instrument. The Bosch instrument exhibited as much as $16 \mathrm{~dB}$ more gain below $1 \mathrm{kHz}$ than the Unitron instrument and as much as $5 \mathrm{~dB}$ less gain from $2 \mathrm{kHz}$ through $3.15 \mathrm{kHz}$. The Bosch instrument rolled off at $5 \mathrm{kHz}$ while the Unitron aid exhibited a $12 \mathrm{~dB}$ gain at $6.3 \mathrm{kHz}$, the frequency limit of the Fonix FP-20 analyzer.

\section{TABLE X}

MEAN AUDIOMETRIC THRESHOIDS IN DB HL OF SUBJECTS RECEIVING HEARING AID EVALUATIONS

(HAEs) IN NOISE

\begin{tabular}{c|c|c|c|c|c|c|c|c|c} 
& 250 & 500 & 1000 & 2000 & 3000 & 4000 & 6000 & 8000 & $\mathrm{~Hz}$ \\
$\mathrm{yyyyyyyyy} \mathrm{X}$ & 8.5 & 9.5 & 13 & 59 & 66 & 73 & 76.5 & 75.5 & $\mathrm{~dB} \mathrm{HL}$ \\
\cline { 2 - 9 } $\mathrm{SD}$ & 5.5 & 4.7 & 4.6 & 5.0 & 8.6 & 14.2 & 15.2 & 7.6 & $\mathrm{~dB} \mathrm{HL}$ \\
\cline { 2 - 9 } & $0-20$ & $5-20$ & $0-15$ & $50-70$ & $55-85$ & $60-105$ & $65-115$ & $65-90$ & $\mathrm{~dB} \mathrm{HL}$
\end{tabular}

TABLE XI

MEAN AUDIOMETRIC THRESHOLDS IN dB HL OF SUBJECTS RECEIVING HEARING AID EVALUATIONS

(HAES) IN QUIET

\begin{tabular}{c|c|c|c|c|c|c|c|c|c|} 
& 250 & 500 & 1000 & 2000 & 3000 & 4000 & 6000 & 8000 & $\mathrm{~Hz}$ \\
\hline $\mathrm{x}$ & 7.27 & 10.45 & 10.9 & 58.64 & 65 & 69.5 & 75.45 & 79.55 & $\mathrm{~dB} \mathrm{HL}$ \\
\cline { 2 - 9 } $\mathrm{SD}$ & 5.8 & 4.5 & 5.1 & 5.7 & 5.6 & 9.2 & 13.9 & 14.2 & $\mathrm{~dB} \mathrm{HL}$ \\
\cline { 2 - 9 } & $0-20$ & $5-20$ & $0-15$ & $50-70$ & $55-75$ & $60-95$ & $65-110+$ & $65-110+$ & $\mathrm{dB} \mathrm{HL}$
\end{tabular}

The real ear frequency responses, as obtained by the acoustimed HA-2000 spectrograph probe microphone system, are presented for each study in Figures 3 and 4 . The 
corresponding aided gain levels for the respective groups are indicated in Figures 5 and 6 . Six to $11 \mathrm{~dB}$ more gain was revealed with the Bosch hearing aid from $.67 \mathrm{kHz}$ through $1.3 \mathrm{kHz}$ than with the Unitron aid. At the primary peak of $2.3 \mathrm{kHz}$, the Unitron aid in this study revealed a maximum real ear gain of only 3-5 dB over the Bosch aid. The next difference between the two aids occurred beyond $4 \mathrm{kHz}$ where the Unitron instrument had up to $13 \mathrm{~dB}$ gain over the Bosch aid.

\section{TABLE XII}

MEANS, STANDARD DEVIATIONS AND RANGES OF NU-6 DISCRIMINATION PERCENTAGE SCORES EVALUATED IN NOISE AND QUIET OBTAINED AT MCL WITH HEADPHONES

$\begin{array}{cc}\text { DISCRIMINATION } & \text { DISCRIMINATION } \\ \text { SCORES FOR } & \text { SCORES FOR } \\ \text { SUBJECTS } & \text { SUBJECTS } \\ \text { RECEIVING } & \text { RECEIVING } \\ \text { HAE (S) IN NOISE } & \text { HAE(S) IN QUIET }\end{array}$

$\begin{array}{rcc}X & 76.8 & 78.9 \\ \mathrm{SD} & 7.0 & 7.25 \\ \mathrm{R} & 58-84 & 58-88\end{array}$

The mean CCT and NU-6 scores, standard deviations and ranges are listed in Table XIII for those tested in noise and in Table XIV for those tested in quiet. Correspondingly, the mean levels of aided improvement found with each aid are presented in Table XV for both sets of conditions. The individual subject scores for the NU-6 and CCT results in noise are presented in Appendix $A$ and those for the HAE results in quiet are in Appendix $B$. 
PABLE XIII

UNAIDED AND AIDED MEAN DISCRIMINATION PERCENTAGE SCORES, STANDARD DEVIATIONS AND RANGES OF SUBJECTS WITH PRECIPITOUS HIGH FREQUENCY LOSSES, TESTED IN NOISE

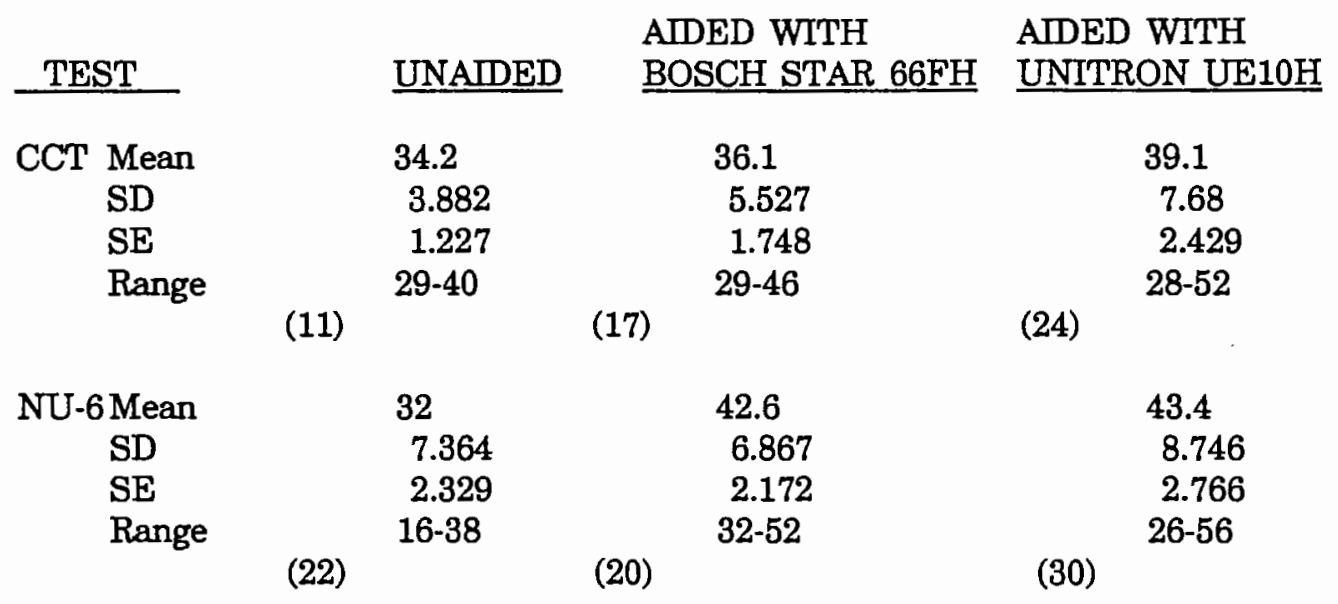

Subjects evaluated in noise yielded a mean CCT unaided score of 34.28 and increased aided scores of 36.18 using the Bosch Star 66F H and 39.18 using the Unitron UE $10 \mathrm{H}$. Their unaided NU-6 scores were 32\%, and their Bosch/Unitron aided scores were 42.68 and 43.48 , respectively. Thus in noise, the Unitron aid provided a mean CCT increase of 4.98 over the unaided condition whereas the Bosch aid yielded a 1.98 CCT increase. When NU-6 recordings were used, the Unitron instrument again yielded slightly higher mean aided scores than the Bosch instrument with an 11.48 versus a 10.68 improvement over the unaided condition. 
TABLE XIV

UNAIDED AND AIDED MEAN DISCRIMINATION PERCENTAGE SCORES, STANDARD DEVIATIONS, STANDARD ERRORS AND RANGES OF SUBJECTS WITH PRECIPITOUS HIGH FREQUENCY LOSSES, TESTED IN QUIET

TEST

CCT Mean

$\mathrm{SD}$

$\mathrm{SE}$

Range

(41)

NU-6 Mean

SD

SE

Range
UNAIDED

56.727

11.42

3.443

$32-73$

(41)

72.909

14.625

4.41

$46-88$

(42)

63.273

12.418

3.744

$37-78$

82.182

10.486

3.162

$58-92$

(34)
AIDED WITH AIDED WITH

BOSCH STAR 66 FH UNITRON UE10H
61.364

10.838

3.268

46-76

(30)

80.364

10.23

3.084

56-92
(36)

TABLE XV

AIDED IMPROVEMENT IN DISCRIMINATION PERCENTAGE SCORES OF SUBJECTS WITH PRECIPITOUS HIGH FREQUENCY LOSSES

\section{TEST CONDITION}

Noise $(\mathbf{n}=10)$

Bosch Star 66F H

Unitron UE10H

Quiet $(\mathrm{n}=11)$

Bosch Star 66F H

Unitron UE10H
$\underline{\mathrm{NU}-6}$

$10.6 \%$

$11.4 \%$

$9.273 \%$

$7.455 \%$
$\underline{\mathrm{CCT}}$

$1.9 \%$

$4.9 \%$

$6.546 \%$

$4.637 \%$ 


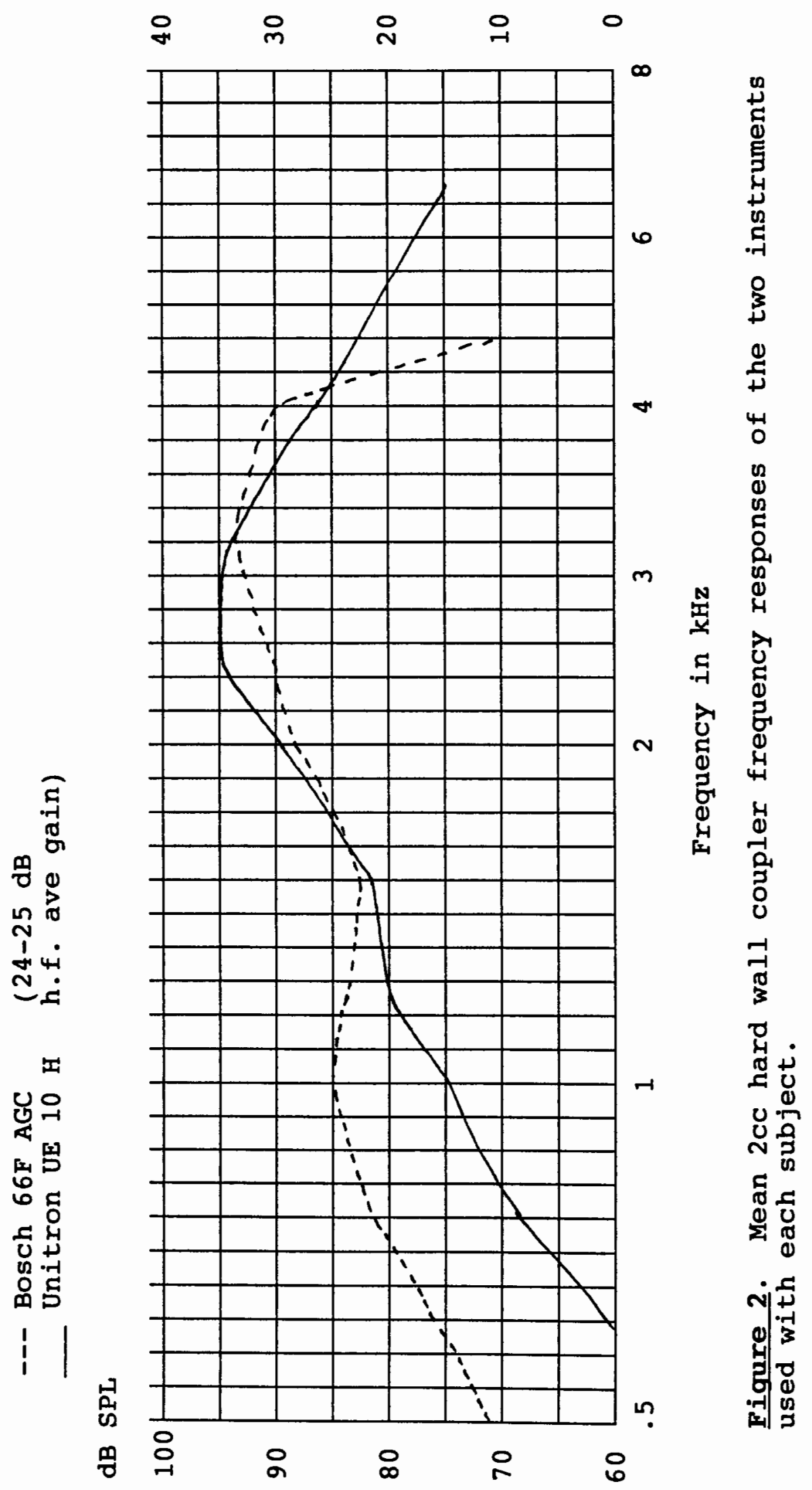




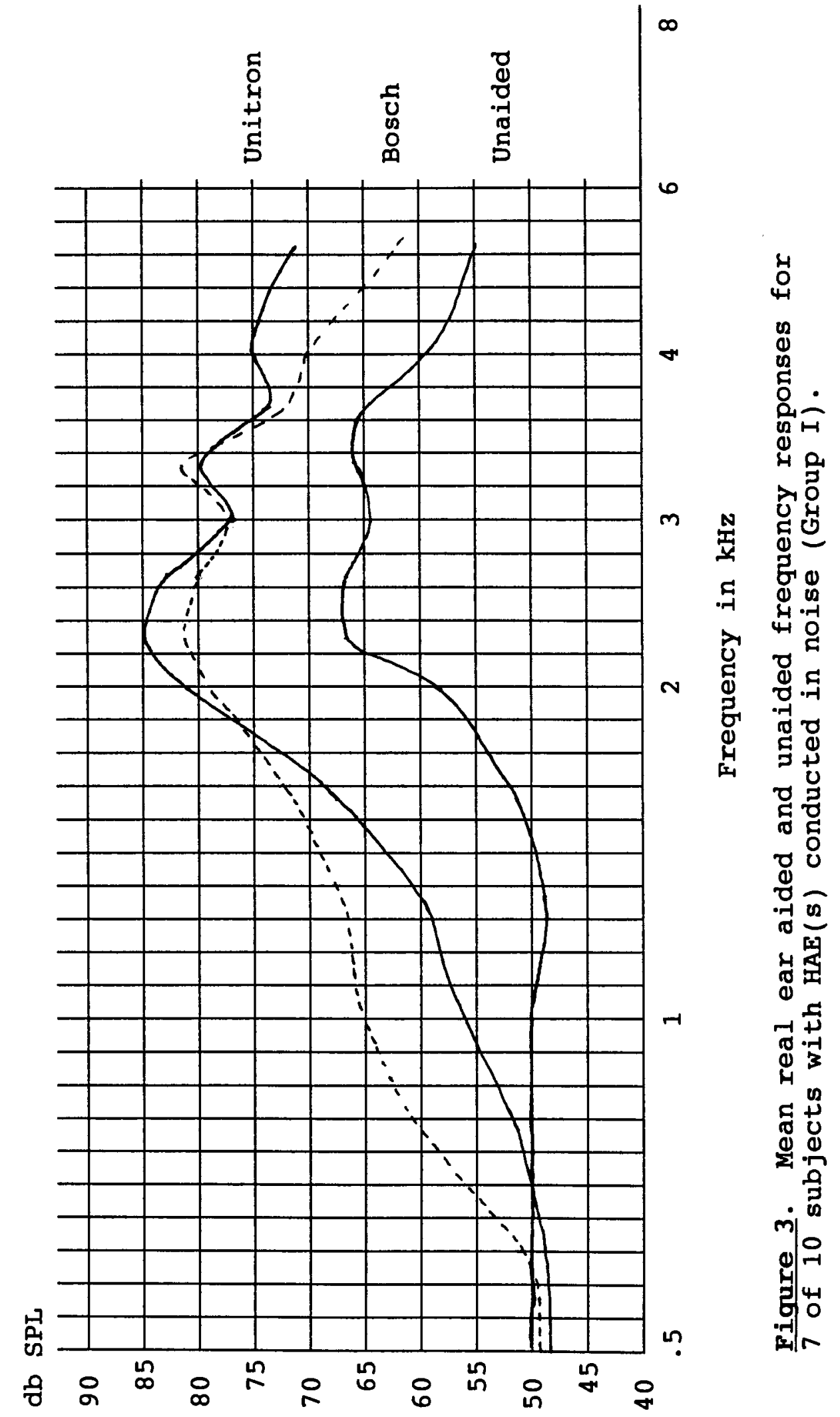




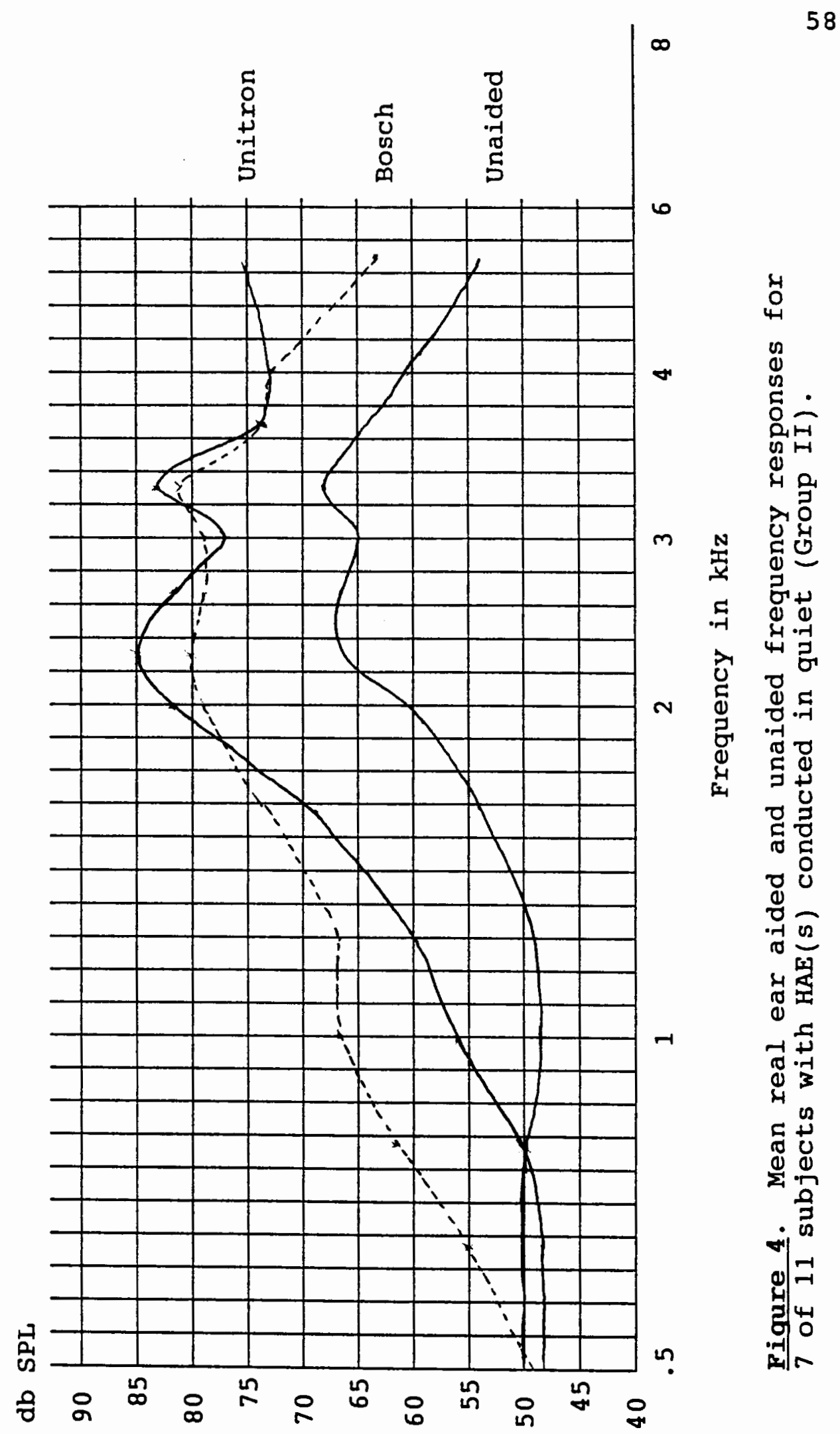




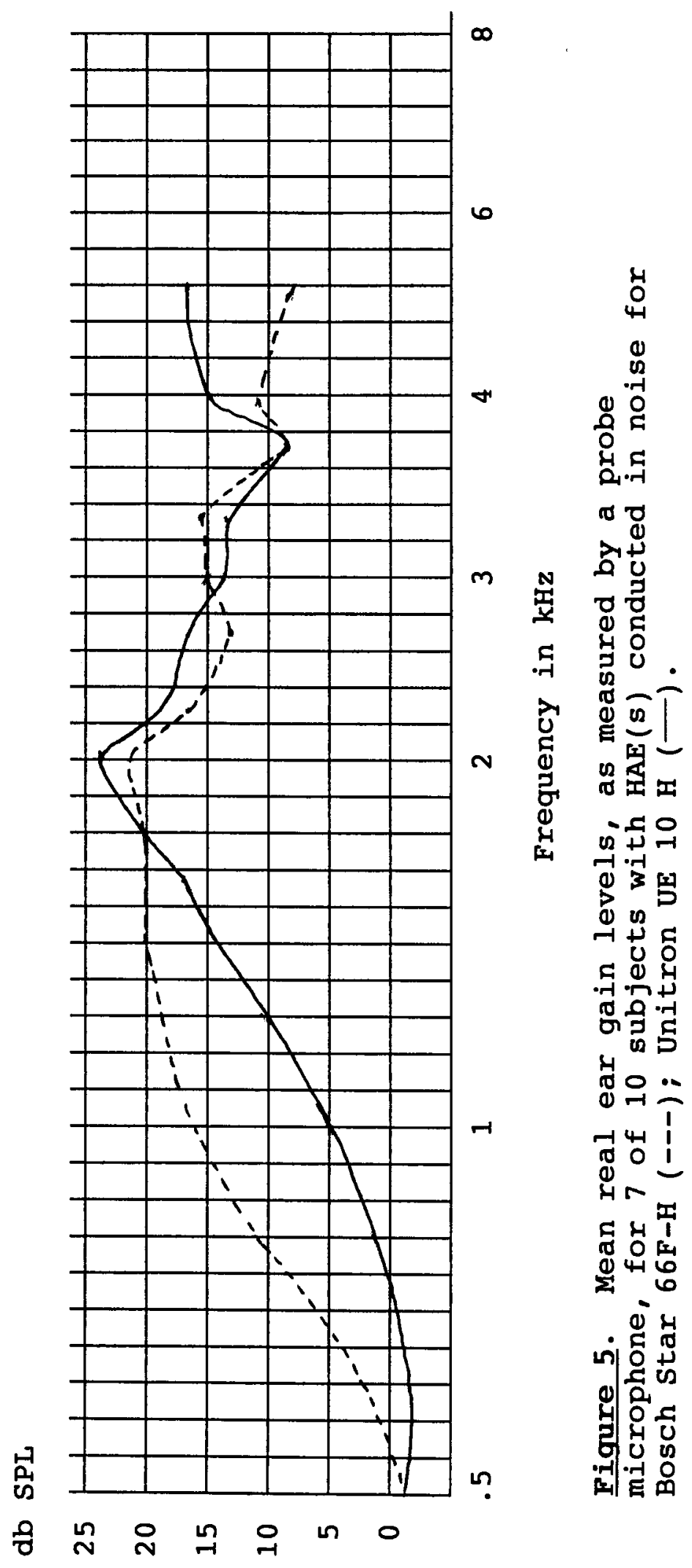




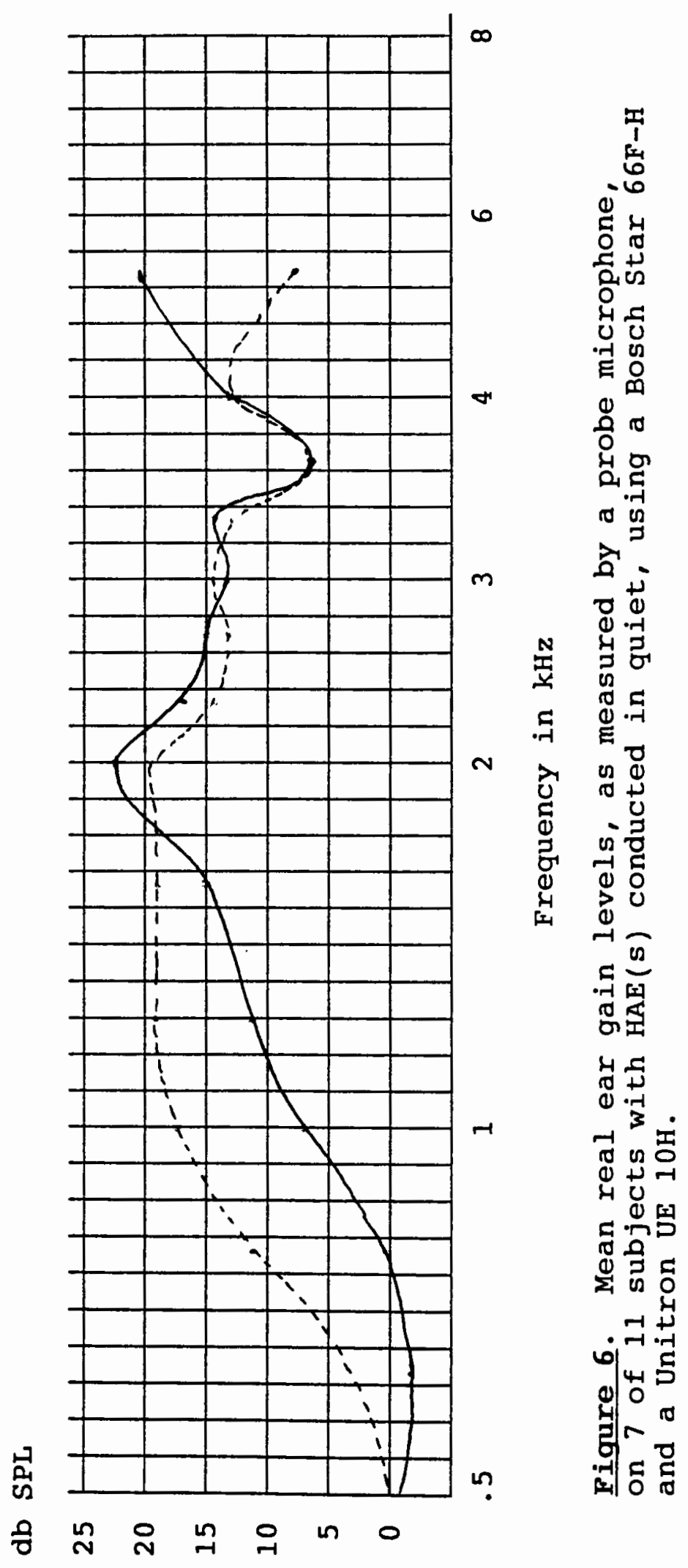


In this condition of noise, the one-way analysis of variance for repeated measures (ANOVA) did not revea1 a significant difference between the mean aided performances with either the CCT or the NU-6 recordings at the .01 level of confidence. It likewise did not find a significant difference in noise when either of the mean aided CCT scores were compared with the mean unaided CCT scores $(p<.0498)$ (Table XVI). However, a significant difference ( $\mathrm{p}<.0001$ ) was found between the aided and unaided conditions for the NU-6 word list. The Scheffe follow-up test (Winer, 1971) found a significant difference at the .01 level of confidence between the mean unaided and aided NU-6 scores for both the Bosch and Unitron hearing aids.

Subjects evaluated in quiet revealed mean unaided, Bosch and Unitron CCT scores of $56.78,63.38$ and $61.4 \%$, respectively. The corresponding mean NU-6 scores were $72.98,82.28$ and 80.48 . In quiet, therefore, the Bosch scores were slightly higher than the Unitron scores. The aided over unaided CCT improvement was 6.58 with the Star $66 \mathrm{~F} \mathrm{H}$ and only 4.68 with the UE-10H, a difference of 1.98 between the two aids. The improvement noted with the NU-6 recording was 9.38 with the lower frequency instrument and 7.58 with the higher pass aid, a difference of $1.8 \%$.

In this quiet condition, the one-way ANOVA (Table XVII) again did not reveal a significant difference at the .01 level of confidence between the mean Unitron and Bosch aided 
performances with either the CCT or NU-6. A lack of statistically significant difference at the .01 level of confidence was also noted when the mean in quiet Unitron aided performances were compared with the corresponding mean unaided performances. This was true with both the CCT scores $(p<.0054)$ and the NU-6 scores $(p<.0094)$. ANOVA results for the unaided versus Bosch scores, however, did find a statistically significant difference at the .01 level using the Scheffe F-test with the CCT. A significant difference at the .01 level of confidence between unaided and Bosch scores using the Fisher Protected Least Significant Difference (PLSD) (Winer 1971) follow-up test was found with the NU-6. 
TABLE XVI

ONE WAY ANALYSIS OF VARIANCE FOR REPEATED MEASURES (ANOVA) FOR UNAIDED AND AIDED CCT AND NU-6

SCORES OF SUBJECTS EVALUATED IN NOISE

CCT

\begin{tabular}{|c|c|c|c|c|c|}
\hline Source & $\underline{\mathrm{Df}}$ & Sum OF Squares & Mean Squares & F-Test & $\underline{\mathrm{P} \text { Value }}$ \\
\hline Between subjects & 9 & 632.8 & 70.311 & 3.265 & .0132 \\
\hline Within subjects & 20 & 430.667 & 21.533 & & \\
\hline Treatments & 2 & 122.067 & 61.033 & 3.56 & .0498 \\
\hline Residual & 18 & 308.6 & 17.144 & & \\
\hline Total & 29 & 1063.467 & & & \\
\hline \multirow{2}{*}{\multicolumn{3}{|c|}{$\begin{array}{r}\text { Reliability Estimate For All Treatments: .694 } \\
\text { NU-6 }\end{array}$}} & \multirow{2}{*}{\multicolumn{3}{|c|}{ Single Treatment: .43}} \\
\hline & & & & & \\
\hline Source & $\underline{\mathrm{Df}}$ & Sum of Squares & Mean Square & F-Test & P Value \\
\hline Between subjects & 9 & 1114.667 & 123.852 & 1.911 & .1092 \\
\hline Within subjects & 20 & 1296 & 64.8 & & \\
\hline Treatments & 2 & 809.867 & 404.933 & 14.993 & .0001 \\
\hline Residual & 18 & 486.133 & 27.007 & & \\
\hline Total & 29 & 2410.667 & & & \\
\hline \multicolumn{3}{|c|}{ Reliability Estimates For All Treatments: .477} & \multicolumn{3}{|c|}{ Single Treatment: .233} \\
\hline Comparison & & Mean Difference & \multicolumn{3}{|c|}{ Scheffe F-Test } \\
\hline Unaided vs. Bosch & & $\overline{-10.6}$ & \multicolumn{3}{|c|}{$10.401^{*}$} \\
\hline Unaided vs. Unitron & & -11.4 & \multicolumn{3}{|l|}{$12.03^{*}$} \\
\hline Bosch vs. Unitron & & -.8 & \multicolumn{3}{|l|}{.059} \\
\hline
\end{tabular}

*Significant at .01 level of confidence. 


\section{TABLE XVII}

\section{ONE WAY ANALYSIS OF VARIANCE FOR REPEATED MEASURES (ANOVA) FOR UNAIDED AND AIDED CCT AND NU-6 \\ SCORES OF SUBJECTS EVATUATED IN QUIET}

\section{CCT}

\begin{tabular}{|c|c|c|c|c|c|}
\hline Source & Df & Sum OF Squares & Mean Squares & F-Test & P Value \\
\hline$\overline{\text { Between subjects }}$ & $\overline{10}$ & 3657.515 & 365.752 & 13.134 & .0001 \\
\hline Within subjects & 22 & 612.667 & 27.848 & & \\
\hline Treatments & 2 & 249.273 & 124.636 & 6.86 & .0054 \\
\hline Residual & 20 & 363.394 & 18.17 & & \\
\hline
\end{tabular}

$\begin{array}{lll}\text { Total } & 32 & \mathbf{4 2 7 0 . 1 8 2}\end{array}$

Reliability Estimate For All Treatments: .924

Comparison

Unaided vs. Bosch

Mean Difference

$-6.545$

Unaided vs. Unitron

$-4.636$

1.909

Bosch vs. Unitron

*Significant at .01 level of confidence.

NU-6

Source

Between subjects

Df $\quad$ Sum of Squares

3392.242

Within subjects

Treatments

Residual

$22 \quad 1424$

$2 \quad 531.152$

$20 \quad 892.848$

$32 \quad 4816.242$

Total

$32 \quad 4816.242$

Reliability Estimates For All Treatments: .809

Comparison

Unaided vs. Bosch

Unaided vs. Unitron

Bosch vs. Unitron
Mean Difference

$-9.273$

$-7.455$

1.818
Mean Square F-Test $P$ Value 339.224

$5.241 \quad 0006$

64.727

265.576

44.642
Scheffe F-Test

$6.484^{*}$

3.253

.552

*Significant at 01 level of confidence.

Single Treatment: .586

Scheffe F-Test Fisher PLSD

5.297

8.107

3.423

8.107

.204

8.107 


\section{DISCUSSION}

The mean 2cc coupler and real ear frequency responses of the Bosch Star $66 \mathrm{~F} \mathrm{H}$ and the Unitron UE-10H used in this study did not differ as much as the coupler and functional gain responses of the extended high pass Oticon Ell HC differed from that of its unspecified counterparts in the study by Schwartz et al. (1979). This was done to further evaluate the sensitivity of the CCT and NU-6 in detecting significant differences in $\operatorname{HAE}(\mathbf{s})$.

The high frequency impairments evaluated in this study, likewise had a more precipitous drop to their audiometric configuration than the impairments evaluated in previous CCT/NU-6 studies. The question was asked: would mean CCT results be more sensitive than the NU-6 results in revealing a statistically significant difference between the aided performances or the unaided-aided performances of these particularly high frequency impaired subjects or would the acoustic differences be too small to be reflected in the subject's performances?

By using the one-way analysis of variance for repeated measures in the analysis of this data, it was possible to focus separately on the CCT and/or the NU-6 to see if by themselves they could reveal statistically significant differences in the interactions of the various conditions paired against each other. For the $\operatorname{HAE}(s)$ in noise, the mean CCT scores were unable to reveal a significant aided 
improvement with either of the aids, whereas the mean NU-6 results in noise were able to reveal significant aided improvements with both aids. It would seem, therefore, that with the extremely precipitous nature of hearing losses evaluated in this study, and with their associated increased reduction in discrimination over other high frequency losses, the effectiveness of the CCT was not improved but actually reduced in comparison to the NU-6 with the application of noise. The unaided CCT results in quiet were sufficiently reduced to allow for aided improvement with the Bosch instrument but not with the Unitron instrument. The NU-6 results in quiet revealed an advantage of the Bosch aid over the Unitron instrument, at a .01 level of confidence. So, in quiet the CCT and NU-6 appeared to be more equally sensitive. But the addition of the noise to the CCT task, already heavily weighted with phonemes proven to be especially difficult with even mild high frequency losses, apparently was made too difficult for the precipitous losses evaluated in this study. This would seem to account for the contrasting findings of Schwartz, et al. (1979), where the CCT and NU-6 each were able to reveal essentially the same significant aided improvement with the extended high pass aid only when noise was added to the test condition. With the moderate to severe precipitous losses focused on in the herein described studies, the CCT, already difficult in quiet, was simply made too difficult in noise. The 
components of speech targeted with CCT lost to the subject when unaided were more detectable when sufficiently amplified in quiet, but too overly masked when noise was applied for improved detection when aided. 


\section{CHAPTER V}

\section{SUMMARY AND IMPLICATIONS}

\section{SUMMARY}

A variety of speech discrimination tests have been used to evaluate the aided benefits of hearing instruments. Danhauer, et al. (1977) found that discrimination became more difficult as the task ranged from sentences to isolated consonant-vowel (CV) syllables.

Discrimination tasks using conventional sentences in hearing and evaluations (HAEs) have included those developed by Utley (1946), Jeffers and Barley (1976) and Alpiner (1982). Jerger and Hayes (1976) applied the Synthetic Sentence Identification Test (SSI) to $\operatorname{HAE}(s)$ because of its reduced semantic and contextual cues. Zerlin (1962) had subjects compare aided presentations of a thirty second passage of speech, an approach which has been applied in several formats (Punch and Parker, 1981; Montgomery, et al., 1982 and Studebaker, et al., 1982).

Early closed set lists using monosyllabic words included the Fairbank's rhyme test (1958), and the Modified Rhyme Test (House, et al., 1965). Contrastingly, both the Nonsense Syllable Test (NST) by Resnick, et al. (1975) and the Distinctive Features Difference Test (DFD) by Feeney and 
Franks (1982) relied on single syllable discrimination tasks that have been recommended for $\operatorname{HAE}(s)$.

But the most commonly used procedures have been open set monosyllabic word tests such as the CID Auditory Test W-22 (Hirsh, et al., 1952), and, more currently, the Northwestern University's NU-6 lists (Tillman and Carhart, 1966). But even the NU-6 lists have lacked the sensitivity especially needed for $\operatorname{HAE}(s)$ (Maroonroge and Diefendorf 1984).

In 1977 Owens and Schubert introduced the California Consonant Test with its closed set response format and reportedly increased sensitivity to high frequency losses. Those with precipitous losses were found to have significantly lower scores when evaluated with the CCT than with NU-6 recordings. In noise and quiet Schwartz, et al. (1979) used CCT and NU-6 recordings as well as an eight voiceless consonant test to compare a conventional and extended high pass aid on subjects with mild to moderate precipitous losses above $1 \mathrm{kHz}$. The CCT consistently revealed lower scores than the NU-6 recordings, but none of the tests (including the consonant test) showed significant differences between aided performances in quiet. Significant differences, however, were found in quiet with all three tests.

In the current study, two groups with moderate to severe precipitous losses beyond $1 \mathrm{kHz}$ were evaluated with $\mathrm{NU}-6$ and CCT recordings using two conventional high pass aids. The 
two instruments had smaller high frequency response differences and greater low frequency differences than the aids evaluated by schwartz, et al. (1979). Some differences were found between aided versus unaided performances in quiet and in noise, but none were found between aided performances themselves.

\section{IMPLICATIONS}

The subjects of both the groups analyzed in this study were faced with some difficult discrimination tasks. Because of their abrupt losses in high frequency sensitivity and their correspondingly reduced ability to discriminate, their auditory systems, especially in noise, were greatly taxed. It was because of this uniqueness from other hearing loss configurations that they were made the focus of this study. And it would seem, also due to this uniqueness, the results of this study have varied in some respects from the results of other studies involving the CCT and/or the NU-6 recordings. The results, when viewed separately, and also when compared to those of other investigations, have indicated a number of clinical implications that should be born in mind.

The NU-6 is a common clinical tool in audiologic evaluations, and the statistical analysis of this study indicates that it consistently was able to reveal more significant differences between precipitous loss 
performances in noise than the CCT. In quiet, depending on which ANOVA follow-up test was used, they seemed to be equally sensitive. Because it takes less time to administer, however, the NU-6 might be the clinical tool of choice rather than the CCT when evaluating the discrimination abilities of the precipitous losses herein evaluated.

However, there were individuals with these precipitous losses who may have fared too well unaided with the NU-6 in quiet for the NU-6 to realistically demonstrate a sensitivity toward aided improvement on the 100 point scale, let alone allow for a potential significant difference between the two aided conditions. This particularly seemed to be the case with the four subjects who achieved unaided NU-6 scores of $88 \%$. In such cases, perhaps noise could be applied to increase the sensitivity for effective clinical use of the NU-6, or the CCT could be employed in quiet to allow for sufficient degrees of aided improvement. For some patients, especially those looking into amplification for the first time or those with limiting recruitment or reduced psychological tolerance of noise, $\operatorname{HAE}(s)$ in quiet may be less stressful. The CCT may be the appropriate choice over the NU-6 when conducting aided evaluations with these individuals.

These conclusions are based on only one small study when more studies are clearly needed. The precipitous losses 
evaluated in this investigation represent more than just another type of high frequency loss such as the less severe impairments evaluated by Schwartz, et al. (1979). Because of their frequency-specific abrupt onset, they carried with them special acoustic problems that are not otherwise encountered and thus need to be the specific focus of additional research. Schwartz, et al. (1979) found positive results with the CCT and their nonsense syllable evaluations in quiet that they did not find with the NU-6 recordings, whereas the NU-6 and CCT seemed to exhibit equal sensitivity in quiet during the current study. But the mean audiometric configurations of the Schwartz, et al. (1979) study revealed losses at $2 \mathrm{kHz}$ that were $15 \mathrm{~dB}$ milder than those of this study. In view of these conflicting results, precipitous losses of the herein evaluated magnitude need to be the specific focus of future studies. As this becomes the focus for research, other tests, such as nonsense syllable tests that target high frequency components of speech should be investigated.

Neither of the conventional high pass aids utilized here boosted the high frequency energy as well as did the experimental extended high pass aid employed by Schwartz, et al. (1979). It was with that instrument that the CCT had shown the greatest advantages over the NU-6. Perhaps the CCT would have fared better with the type of precipitous loss focused on in this study if one conventional high-pass 
aid had been contrasted with a more extended high pass aid such as the oticon El1HC evaluated by Schwartz, et al.

(1979). With that instrumentation, the components of speech targeted by the CCT might have been perceived more effectively by the individuals with these difficult to fit hearing losses. The CCT, therefore, might still be the discrimination test of choice over the NU-6 when evaluating extended high-pass aids in quiet or individuals with these precipitous losses.

Beyond the questions addressing which discrimination tasks should be used with various audiometric configurations, and various hearing aids or types of aids, this study broached the clinical benefit of probe microphones. The Acoustimed HA-2000 Real Ear Spectroscope revealed acoustic differences between aids not revealed by either the CCT or the NU-6. Volumes of research have been compiled and studies are still underway involving the use of probe microphones in conjunction with the long standing use of discrimination tasks in $\operatorname{HAE}(s)$.

Speech lists are still an important component of the HAE because they monitor some of the processing and perceptual realms important in any hearing aid fitting (Flores, 1988; Humes, 1988; Trede, 1988). But accurate acoustic measurements at or near the tympanic membrane can quickly and efficiently evaluate the effects of a change of hearing aids, the adjustment of their trim pots, and the alteration 
of their ear mold parameters before any time consuming discrimination testing is required (Jelonek, 1988; Libby, 1988; Trede, 1988).

Probe microphones can reveal the effects of maximum power output (MPO) adjustments (Harford, 1980; Hawkins 1988; Popelka, 1988; Seewald, 1988; and Upfold, 1988). Those using a real time mode can monitor the function of automatic gain control (AGC), automatic signal processing (ASP), Zeta Noise Blocker ${ }^{T M}$ and MSP ${ }^{T M}$ systems (Jelonek, 1988). Probe microphones can evaluate the smoothness of aided frequency responses and detect spikes unnoticed with functional gain measurements (Trede, 1988). Generally, the preliminary choice and adjustment of hearing aids and ear molds for any number of prescriptive methods of selecting hearing aids such as the Berger, CID, Cox, Libby, Revised NAL (National Acoustic Laboratory), POGO (prescription of gain and output), SHAPE (selecting hearing aids for patients effectively) and Desired Sensation Level methods can be performed with a reliable probe system much more efficiently than if a discrimination task was assigned for each adjustment separately (Libby, 1988). 


\section{SELECTED REFERENCES}

ALPINER, J.G. Evaluation of communication function. Handbook of Adult Rehabilitative Audiology. Alpiner (ed.), Baltimore: Williams and Wilkins, 1982.

AMERICAN NATIONAL STANDARDS INSTITUTE, American National Standard Specifications for Audiometers. ANSI 53.61969 New York, 1969.

AMERICAN NATIONAL STANDARDS INSTITUTE, American National Standard Specifications of Hearing Aid Characteristics. ANSI S 3.22-1982 New York, 1982 .

BILGER, R.C., \& WANG, M.D. Consonant confusion in patients with sensorineural hearing loss. Journal of Speech and Hearing Research, 1976, 19, 718-748.

CARHART, R. Tests for selection of hearing aids. Laryngoscope, $1946,56,780-794$.

CHARI, N.C.A., HERMAN, G. \& DANHAUER, J.L. Perception of one-third octave-band filtered speech. Journal of the Acoustic Society of America, 1977, 61, 576-580.

DANHAUER, J. L., CHARI, N.C. \& HERMAN, G. Normal-hearing subjects perception of speech through one-third octave bands. Journal of Auditory Research, 1977, 17, 275281 .

DANHAUER, J.L., \& LEPPLER, J.G. Effects of four noise competitors on the California consonant test. Journal of Speech and Hearing Disorders, 1979, 44, 354-362.

DODDS, E. \& HARFORD, E. Application of a lipreading test in a hearing aid evaluation. Journal of Speech and Hearing Disorders, $1968,33,167-173$.

DUBNO, J.R., DIRKS, D.D., \& LANGHOFER, L.R. Evaluation of hearing impaired listeners using a nonsense-syllable test. II syllable recognition and consonant confusion patterns. Journal of Speech and Hearing Research, 1982, $25,141-148$.

EGAN, J.P. Articulation testing methods. Laryngoscope, $1948,58,955-991$. 
ELDERT, E. \& DAVIS, H. The articulation function of patients with conductive deafness. Laryngoscope, 1951, 61, 896-909.

FAIRBANKS, G. Test of phonemic differentiation: the rhyme test. Journal of the Acoustic Society of America, 1958, $30,596-600$.

FEENEY, M.P. \& FRANKS, J.R. Test-retest reliability of a distinctive feature difference list for hearing aid evaluation. Ear and Hearing, 1982, 3, 59-65.

FLORES, Z. Real ear measurements: Where are we today? Hearing Instruments, 1988, 39, 41-42.

GEFFNER, D. , \& DONOVAN, N. Intelligibility functions of normal and sensorineural loss subjects of the $\mathrm{W}-22$ lists. Journal of Auditory Research, 1974, 14, 82-86.

GERBER, S. Introductory Hearing science. Philadelphia: W.B. Sannders, 1974 .

GOETZINGER, C.P. Word discrimination testing. Handbook of Clinical Audiology. Katz (Ed.), Baltimore: Williams and Wilkins, 1978 .

HARFORD, E.R. The use of a minature microphone in the ear canal for the verification of hearing aid performance. Ear and Hearing, 1980, 1, 329-337.

HARRIS, K.D., HAINES, H., \& MYER, C. The importance of hearing at $3 \mathrm{kHz}$ for understanding speeded speech. Laryngoscope, 1960, 70, 131-146.

HAWKINS, D.B. Some opinions concerning real ear probe tube measurements. Hearing Instruments, $1988,39,28$.

HAYES, D., JERGER, J., TAFF, J. \& BARBER, B. Relation between aided synthetic sentence identification scores and hearing aid user satisfaction. Ear and Hearing, $1983,4,158-61$.

HIRSH, I., DAVIS, H., SILVERMAN, S. , REYNOLDS, E. , ELDERT, E., \& BENSON, R. Development of materials for speech audiometry. Journal of Speech and Hearing Disorders, $1952,17,321-337$.

HOUSE, A., WILLIAMS, C., HECKER, M., \& KRYTER, $\mathrm{K}$. Articulation testing methods: Consonant differentiation with a closed response set. Journal of the Acoustic Society of America, $1965,37, \frac{158-166}{1}$. 
HUMES, L.E. And the winner is . - Hearing Instruments $1988,39,24-26$.

JEFFERS, J. \& BARLEY, M. (eds.). Speechreading Lipreading. Springfield: Charles C. Thomas, 1976.

JELONEK, S. Practical in-office applications for probe microphone systems. Hearing Instruments, 1988, 39, 3035 .

JERGER, J. \& HAYES, D. Hearing aid evaluation: Clinical experience with a new philosophy. Archives of Otolaryngology, 1976, 102, 214-225.

KREUL, E.J., BELL, D., \& NIXON, J.C. Factors affecting speech discrimination test difficulty. Journal of Speech and Hearing Research, 1968, 12, 281-287.

KREUL, E.J., NIXON, J.C., BELL, D.W., KRYTER, K.D., LLANG, J.S., \& SCHUBERT, E.D. A proposed clinical test of speech discrimination. Journal of Speech and Hearing Research, 1969, 11, 536-552.

LIBBY, R.E. Hearing aid selection strategies and probe tube microphone measures. Hearing Instruments, 1988, 39, 1015 .

MAROONROGE, S., \& DIEFENDORF, A.O. Comparing normal hearing and hearing impaired subjects performance on the northwestern auditory test number 6 , Califormia Consonant Test, and Pascoe's high frequency word test. Ear and Hearing, 1984, 5, 356-60.

MILLER, G.A., HEISE, G., \& LICHTEN, w. The intelligibility of speech as a function of the context of the test materials. Journal of Experimental Psychology, 1951, $41,329-335$.

MONTGOMERY, A., SCHWARTZ, D. \& \& PUNCH, J. Tournament strategies in hearing aid selection. Journal of Speech and Hearing Disorders, 1982, 47, 363-372.

ORCHIK, D., \& RODDY, N. The SSI and NU-6 in clinical hearing aid evaluation. Journal of Speech and Hearing Disorders, $1980,45,401-407$.

OWENS, E., BENNEDICT, M., \& SCHUBERT, E.D. Further investigation of vowel items in multiple-choice discrimination testing. Journal of speech and Hearing Research, $1971,14,841-847$. 
OWENS, E., BENEDICT, M., \& SCHUBERT, E. Consonant phonemic errors associated with pure tone configurations and certain kinds of hearing impairment. Journal of Speech and Hearing Research, 1972, 15, 308-322.

OWENS, E., \& SCHUBERT, E. The development of consonant items for speech discrimination testing. Journal of Speech and Hearing Research, 1968, 11, 656-667.

OWENS, E., \& SCHUBERT, E. Development of the California consonant test. Journal of speech and Hearing Research, $1977,20,463-474$.

PASCOE, D.P. An approach to hearing aid selection. Hearing Instruments, $1978,29,12-36$.

PENROD, J.P. Speech discrimination testing. Handbook of Clinical Audiology, J. Katz (ed.) 1985.

POPELKA, G.R. The CID method; Phase IV. Hearing Instruments, $1988,39,15-18$.

PUNCH, J.L., \& PARKER, C.A. Pairwise listener performances in hearing aid evaluation. Journal of Speech and Hearing Research, 1981, 24, 366-374.

RESNICK, S.B., DUBNO, J.R., HOFFNUNG, S. \& LEWITT, H. Phoneme errors on a nonsense syllable test. Journal of the Acoustical Society of America, 1975, 58 (Supplement 1), 114 .

RosS, M. Hearing aid evaluation. Handbook of Clinical Audiology. J. Katz (Ed.), 1978 .

SCHEFE, H. The Analysis of Variance. New York: Wiley, 1959 .

SCHUBERT, E.D., \& OWENS, E. CVC words as test items. Journal of Auditory Research, 1971, 11, 88-100.

SCHWARTZ, D., \& SURR, R. Three experiments on the California Consonant Test. Journal of speech and Hearing Disorders, $1979,44,61-72$.

SCHWARTZ, D.M., SURR, R.K., MONTGOMERY, A.A., PROSER, R.A., and WALDEN, B.E. Performance of high frequency impaired listeners with conventional and extended high frequency amplification. Audiology, 1979, 18, 154-174.

SEEWALD, R.C. The desired sensation level approach for children: Selection and verification. Hearing Instruments, $1988,39,18-20$. 
SHER, A., \& OWENS, E. Consonant confusions associated with hearing loss above $2000 \mathrm{~Hz}$. Journal of Speech and Hearing Research, $1974,17,669-681$.

SKINNER, M.W. Speech intelligibility in noise-induced hearing loss: Effects of high frequency compensation. Journal of the Acoustic Society of America, 1980, 67, 306-317.

SPEAKS, C. \& JERGER, J. Method for measurement of speech identification. Journal of Speech and Hearing Research, $1965,8,185-194$.

STUDEBAKER, G.A., BISSET, J.D., VAN ORT, D.M. \& HOFFNUNG, S. Paired comparison judgments of relative intelligibility in noise. Journal of the Acoustic Society of America, $1982,72,80-92$.

SURR, R.K., \& SCHWARTZ, D.M. Effects of multi-talker competing speech on the variability of the California consonant test. Ear and Hearing, 1980, 1, 319-323.

TECCA, J., \& BINNIE, C. The application of an adaptive procedure to the California Consonant test for hearing aid evaluation. Ear and Hearing, 1982, 3, 72-76.

THORNDIKE, E.L. \& LORGE, I. The Teachers Word Book of 30,000 Words. New York: Columbia University Teachers College, 1952 .

TILLMAN, T.W., AND CARHART, R. An expanded test for speech discrimination utilizing CNC monosyllabic words (Northwestern University Auditory Test No. 6). Technical Report, SAM-TR_66-55, USAF School of Aerospace Medicine. Aerospace Medical Division, (AFSC) Brooks Air Force Base, Texas, 1966.

TREDE, K. Real ear measurements: individualized fittings. Hearing Instruments, 1988, 39, 7-8.

UPFOLD, L. The National Acoustic Laboratories instrument selection prodcedure. Hearing Insturments, 1988, 39, 22-24.

UTLEY, J. A test of lipreading ability. The Journal of Speech Disorders, 1946, 11, 109-116.

WINER, B.J. Statistical Principles in Experimental Design. New York: McGraw-Hill, 1971. 
ZERLIN, S. A new approach to hearing aid selection.

Journal of Speech and Hearing Research, 1962, 5, 370376 . 
APPENDIX A

INDIVIDUAL SUBJECT SCORES

FOR UNAIDED AND AIDED CONDITIONS

IN NOISE

SUB

\begin{tabular}{|c|c|c|c|c|c|}
\hline UNA: & & & & UN & RON \\
\hline CCT & NU-6 & CCT & NU-6 & CCT & NU- \\
\hline 38 & 36 & 36 & 48 & 37 & 56 \\
\hline 35 & 38 & 46 & 48 & 43 & 42 \\
\hline 40 & 26 & 35 & 36 & 41 & 40 \\
\hline 29 & 16 & 31 & 34 & 28 & 26 \\
\hline 32 & 26 & 29 & 48 & 34 & 50 \\
\hline 31 & 30 & 33 & 40 & 35 & 38 \\
\hline 38 & 38 & 36 & 42 & 51 & \\
\hline 29 & 36 & 33 & 46 & 35 & \\
\hline 34 & 38 & 45 & 52 & 52 & \\
\hline 36 & 36 & 37 & 32 & 35 & 8 \\
\hline
\end{tabular}




\section{APPENDIX B}

INDIVIDUAI SUBJECT SCORES

FOR UNAIDED AND AIDED CONDITIONS

IN QUIET

\begin{tabular}{|c|c|c|c|c|c|c|}
\hline \multirow[b]{2}{*}{ SUBJECTS } & \multicolumn{2}{|c|}{ UNAIDED } & \multicolumn{2}{|c|}{ BOSCH } & \multicolumn{2}{|c|}{ UNITRON } \\
\hline & $\mathrm{CCT}$ & NU-6 & CCT & $\mathrm{NU}-6$ & $\mathrm{CCT}$ & NU-6 \\
\hline 1 & 54 & 70 & 60 & 80 & 57 & 74 \\
\hline 2 & 49 & 62 & 56 & 68 & 49 & 78 \\
\hline 3 & 58 & 72 & 55 & 90 & 48 & 72 \\
\hline 4 & 32 & 46 & 37 & 58 & 46 & 56 \\
\hline 5 & 55 & 88 & 66 & 84 & 61 & 88 \\
\hline 6 & 55 & 54 & 64 & 90 & 68 & 82 \\
\hline 7 & 72 & 88 & 76 & 88 & 76 & 90 \\
\hline 8 & 73 & 88 & 78 & 92 & 72 & 84 \\
\hline 9 & 67 & 88 & 77 & 86 & 70 & 92 \\
\hline 10 & 53 & 70 & 55 & 80 & 56 & 82 \\
\hline 11 & 56 & 76 & 72 & 88 & 72 & 86 \\
\hline
\end{tabular}

